\title{
¿Cómo se prueba la responsabilidad civil médica en la justicia chilena?
}

\author{
Jorge Larroucau Torres*
}

\begin{abstract}
RESUMEN
En la justicia chilena la responsabilidad civil médica descansa en reglas de entrada y de salida que informan a los litigantes de las cuestiones de hecho que deben ser probadas en cada juicio. Este artículo demuestra que la práctica chilena ha regulado esa prueba al consagrar la soberanía del juez de instancia para decidir los hechos probados y al testimonio médico como la mejor evidencia disponible ante la infracción de un deber de cuidado. La incertidumbre que generan los riesgos terapéuticos ha fomentado el uso judicial de máximas de la experiencia-incluido el res ipsa loquitur-para dirimir los riesgos que cada caso entraña. Esta es una regulación probatoria que se aplica tanto a la responsabilidad que se deriva de un tratamiento (profesionales médicos) como la que se sigue de la organización del servicio de salud (Hospitales y Clínicas).
\end{abstract}

Reglas de prueba - Incertidumbre - Responsabilidad civil médica

\section{How to Prove the Medical Civil Liability in Chilean Justice?}

\begin{abstract}
In Chilean justice medical liability is settled based on rules of entries and exits that inform the litigants of the issues of fact that must be proven in each trial. This paper demonstrates that Chilean practice has regulated the proof of these questions of fact, consecrating the sovereignty of the trial court to decide the proven facts and to the medical testimony as the best available evidence to infringement of a duty of care. The uncertainty of therapeutic risk encourages the judicial use of rules of thumb-including res ipsa loquitur- to settle what risks are inherent to the service. This proof regulation applies whether the liability comes from a treatment (medical professionals) as from the bealth service organization (Hospitals and Clinics).
\end{abstract}

Rules of Proof - Uncertainty - Medical Civil Liability

* Licenciado en Ciencias Jurídicas y Sociales, Universidad de Concepción; Doctor en Derecho, Universidad de Chile. Profesor de Derecho Civil y de Derecho Procesal Civil, Universidad Alberto Hurtado. Correo: jlarrouc@uahurtado.cl. Este artículo forma parte de una investigación que se ha financiado mediante un proyecto Fondecyt Iniciación (No 11121293: "Los estándares de prueba en la justicia civil patrimonial", 2013-2014) cuyo apoyo reconozco y agradezco.

Artículo recibido el 21 de marzo de 2014 y aceptado para su publicación por el Comité Editorial el 29 de octubre de 2014. 


\section{ENTRE RESPONSABILIDAD E INFORTUNIO}

$\mathrm{P}$ ara demostrar que una persona es responsable es necesario encuadrar su conducta dentro de su esfera de competencia segura, o fuera de ella siempre que se trate de una decisión tomada libremente. Esta distinción es básica, pues, como lo notara Joseph Raz, "somos responsables por nuestras conductas porque somos agentes

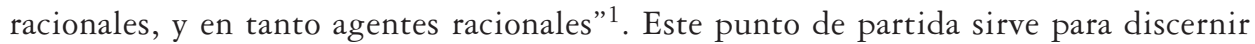
qué ocurre cuando un juez falla que un médico es responsable de los daños sufridos por el paciente o sus familiares. Por cierto, cuando se habla de la responsabilidad de un médico ello vale también para un equipo médico, así como para las empresas y servicios públicos que actúan en este ámbito (Clínicas y Hospitales, según se les llama en lo que sigue). Esta idea común en torno a la responsabilidad civil, como algo crucial en "nuestro sentido de estar en el mundo" ${ }^{2}$, permitirá suspender para los efectos de este trabajo el debate de si la culpa y la falta de servicio son categorías diferentes (en un sentido relevante), así como el empeño por discernir las fronteras (si es que existen) entre la culpa en el marco de un contrato o fuera de él, lo que despejará el terreno para el análisis de la prueba judicial de esa responsabilidad.

De acuerdo con esta idea, un juez decidirá que un médico, Clínica u Hospital es responsable cuando se trata del comportamiento de un agente racional, esto es, de una conducta que ha sido guiada por razones. Desde este punto de vista, el demandado es responsable "cuando las acciones son realizadas en virtud de lo que el agente cree ser una razón adecuada, y su ejecución es controlada y guiada por las creencias de ese agente"3. Estas nociones engloban, nótese bien, las condiciones suficientes para ser considerado responsable, no sus límites, de modo que para delimitar la responsabilidad el Derecho requiere de otras figuras complementarias, entre las que se destaca el estándar de la culpa ("no es responsable quien es diligente") y la causalidad. Esta última, como se verá más adelante, es la predilecta por los jueces chilenos a la hora de fijar los límites de la responsabilidad médica.

Para aterrizar este marco teórico a la experiencia chilena tómese nota de Miranda con Duarte y otros, un caso ocurrido a mediados de los noventa, y varias veces aludido por la literatura civil: un médico cirujano general actuó como anestesista en el Hospital de Puerto Natales, en lo que terminaría con la muerte de la paciente (una mujer de veintiséis años que acababa de dar a luz a su tercer hijo hacía menos de un mes), quien había ido al Hospital a someterse a una cirugía de esterilización tubaria. Su muerte se produjo por un paro cardiorrespiratorio tras las complicaciones que sufrió luego de ser anestesiada por dicho cirujano, quien solo contaba con un entrenamiento de veinte horas en anestesiología. Otro dato importante, ahora en relación con el Hospital, fue que no hubiera en la sala un cardiovector o desfibrilador, pues el único aparato del Hospital

${ }^{1}$ Raz, J., "Responsibility and the Negligence Standard", en Oxford Journal of Legal Studies, Vol. 30, $\mathrm{N}^{\circ} 1,2010$, p. 4.

${ }^{2} \operatorname{Raz}($ n. 1), p. 17.

${ }^{3}$ Raz (n. 1), p. 5. 
estaba en la sala de recuperación de adultos, a más de 45 metros del lugar de la operación. En Miranda, la Corte Suprema decidió que no había responsabilidad por la muerte de la paciente, ya que los demandados fueron, en esas circunstancias, diligentes: ${ }^{4}$ la muerte de la mujer fue un caso de infortunio, no de injusticia.

Miranda muestra claramente cómo el estándar de la culpa (o de la falta de servicio) limita el juicio de responsabilidad. A propósito de esta sentencia, Enrique Barros observó que el estándar de conducta exigido podría no ser el mismo para los médicos que para un Hospital: respecto de los primeros, "la tendencia a la universalización de la formación profesional y del conocimiento [permite] asumir que los estándares de cuidado tenderán progresivamente a ser más homogéneos [pero] más cautela exige la universalización de los requisitos de equipamiento médico y hospitalario" 5 . Esta observación distingue las dos dimensiones -tratamiento y organización- que será necesario tener en cuenta cuando se analice la prueba de la responsabilidad médica. Un aspecto adicional que merecerá la atención es que, como ocurrió en Miranda, el caso puede llegar a ser fallado por la Segunda Sala de la Corte Suprema, la que se encarga de los asuntos penales, ello tiene incidencia en el juicio de hecho, según se verá.

\section{Entradas y salidas}

Este artículo toma en cuenta los deberes de cuidado más que los daños sufridos a efectos de analizar la prueba de la responsabilidad civil médica en la práctica judicial chilena. Para ello se han considerado algo más de dos décadas de jurisprudencia civil, incluidas las decisiones de las Cortes de Apelaciones y de la Corte Suprema. El texto se divide en dos partes. En su primera parte se demuestra cómo las reglas de entrada y de salida de la responsabilidad definen las cuestiones de hecho que deben probarse, sea que se demande por un tratamiento o por la organización del servicio de salud ${ }^{6}$. La experiencia chilena sugiere que las reglas de entrada en el caso de los profesionales de la salud (tratamiento) son más estrechas que en el caso de la organización médica (Hospitales y Clínicas), ya que respecto de los primeros se debe probar una infracción a la lex artis en razón de protocolos y metodologías que han sido fabricados por la propia disciplina médica, mientras que para la organización se han reconocido formas de inferir su responsabilidad (teoría del órgano, culpa organizacional, dependiente anónimo). Pero en cuanto a las reglas de salida, en cambio, ellas son igualmente amplias tanto en

${ }^{4}$ C.S., 02 julio 1998, MJCH_MJJ1014, cons. 6º (Segunda Sala: redacción del Ministro Alberto Chaigneau); también en Revista de Derecho y Jurisprudencia, Tomo XCV, sec. 4a , Fallos del Mes, No 476 y Gaceta Jurídica, $\mathrm{N}^{\circ} 217$.

${ }^{5}$ Barros, E., Tratado de responsabilidad extracontractual, Editorial Jurídica de Chile, Santiago, 2006, p. 671 (n. 43).

${ }^{6}$ La distinción entre reglas de entrada y de salida se toma de Alex Stein, quien a su vez la recoge del trabajo de Grant Gilmore, The Death of Contract (1974), Stein, A., "Toward a Theory of Medical Malpractice", en Iowa Law Review, 97, 2012, p. 1202. 
el tratamiento como en la organización, sea que se acuda al riesgo terapéutico, al error estadístico o a la causalidad.

La segunda parte, en tanto, analiza la forma en que la justicia civil chilena ha regulado la prueba de esta responsabilidad. Los rasgos más llamativos son la soberanía judicial -el juez de instancia tiene competencia exclusiva para fijar los hechos, en una decisión que casi no es controlada por las Cortes- y el uso del testimonio de los propios médicos como la mejor evidencia a la hora de establecer la infracción a un deber de cuidado. El profuso empleo judicial de máximas de la experiencia, cuya mejor versión la ofrece el res ipsa loquitur, es otro de los rasgos que caracterizan a esta prueba en el caso chileno.

De allí, entonces, que el trabajo aborde, primero, el modo en que los deberes de cuidado -como reglas de entrada- inciden en las cuestiones de hecho que los litigantes deben probar, para luego, en la segunda parte, dar cuenta de los principales rasgos de la prueba judicial de esta responsabilidad: el testimonio de los expertos, las máximas de la experiencia, la carga de la prueba y los estándares de prueba. Algunos temas aledaños simplemente serán esbozados, sin recibir un mayor desarrollo. Por último, valga una advertencia acerca del el uso de las palabras: la responsabilidad, como toda otra categoría normativa, no se prueba, de modo que al hablar de la "prueba de la responsabilidad" de lo que se habla es de la prueba de ciertos hechos cuya calificación jurídica hace a alguien responsable. Este aviso toma nota de la división entre hecho y derecho, que funciona bien en términos conceptuales, pero que es algo rígida cuando se la aplica a los procesos judiciales, aunque para los fines de este artículo no resulta polémica.

\section{Deberes de Cuidado y CUESTIONES DE HeCho}

Las condiciones para establecer la responsabilidad civil médica -el guiarse por razones, controlar la conducta y actuar en un ámbito de dominio seguro- fueron recogidas por la Ley $\mathrm{N}^{\circ} 20.584$, vigente desde el $1^{\circ}$ de octubre de 2012, al regular los derechos y deberes de los pacientes en los servicios públicos y privados de salud. Esta ley dejó en claro que los deberes de cuidado van "de la mano" de los derechos en materia de salud", aunque aún queda por discutir si la mejor forma de comprender las reglas de responsabilidad la entrega el binomio deber/derecho o la dupla potestad/responsabilidad. Así, por ejemplo, el derecho de un enfermo terminal "a otorgar o denegar su voluntad para someterse a cualquier tratamiento que tenga como efecto prolongar artificialmente su vida" (Art. 16) anticipa el cuidado que se le debe en su atención; de igual modo, el servicio quedó delimitado por los deberes que el propio paciente y sus familiares tienen para con los prestadores, como el de respetar el reglamento interno del establecimiento de salud (Art. 33) o el deber de informar "de manera veraz acerca de sus necesidades y problemas de salud y de todos los antecedentes que conozcan o les sean solicitados

${ }^{7}$ Raz (n. 1) p. 8 (n. 20). Véase el impacto que tuvo la Convención Europea de Derechos Humanos en la litigación en Inglaterra, Lord Irvine, "The Patient, the Doctor, their Lawyers and the Judge: Rights and Duties”, en Medical Law Review, 7, 1999, pp. 261-263. 
para su adecuado diagnóstico y tratamiento" (Art. 36). Pero el aspecto central de esta ley fue su apuesta por una actualización interna de los deberes de cuidado. Así, aunque la responsabilidad médica todavía descanse en un estándar amplio -la culpa o la falta de servicio- e implique un juicio ex post del comportamiento del demandado, la Ley $\mathrm{N}^{\circ} 20.584$ hizo explícito algo que la jurisprudencia ya había reconocido hace tiempo: esta responsabilidad apela a juicios ex ante estipulados en los protocolos y en los métodos de actuación otorgados por la propia disciplina médica. De allí que esta ley prescriba que los servicios médicos deben cumplir con "las normas vigentes en el país" (lo que incluye tanto a las reglas del contrato, a la culpa como factor de imputación extracontractual, las reglas sobre falta de servicios, así como a las reglas penales, de seguridad del trabajador, protección del consumidor y demás leyes que puedan dictarse) y "con los protocolos establecidos en materia de seguridad del paciente y calidad en la atención” (Art. 4).

Ahora bien, esta forma de confeccionar las reglas de entrada -o de salida, según como se las mire- en la responsabilidad médica, sobre la base de "las prácticas comúnmente aceptadas" (incluida la "atención en salud con pertinencia cultural" en el caso de los pueblos originarios, artículo 7) y a protocolos que informan de "la evidencia científica disponible" (Art. 4), tiene una clara repercusión en la prueba, por lo menos en dos niveles: (i) en primer lugar, el que el Ministerio de Salud sea el único filtro "externo" al contenido de estos protocolos parece un resguardo más bien débil en cuanto a evitar que protejan intereses corporativos de los médicos, Clínicas o de la red de Hospitales, en lugar de orientarse solo a la prevención y cura de las enfermedades. Este punto es relevante porque en Chile la prueba de la responsabilidad médica depende notablemente del testimonio de quienes trabajan en dicha área ("el doctor es quien sabe") ${ }^{8}$. (ii) El segundo reparo es mucho menos práctico a primera vista, pero tiene una incidencia más profunda en la forma de comprender la prueba de los hechos en la responsabilidad médica; se trata de una inquietud que nace en torno a la normatividad de las reglas de la responsabilidad, a cómo estas reglas imponen modelos de conducta, con independencia de si fabricar esas reglas es una tarea primaria de la responsabilidad civil o un "subproducto" del trabajo correctivo de los jueces ${ }^{9}$. La observación se descuelga del éxito que ha tenido el refinar los deberes de cuidado médico en obligaciones de medio y de resultado (aunque "incluso los deberes de tratar son deberes de logro, de lograr tratar") ${ }^{10}$ : que el médico se obligase "a tratar" cuando prestaba su servicio invitó a preguntarse si las reglas de responsabilidad efectivamente daban cuenta de ciertas conductas, es decir, de conductas concretas mediante las cuales el médico iba a cumplir con su compromiso, o todo quedaba entregado a su pericia y "sentido común”. Esta fue la inquietud que

${ }^{8}$ Por supuesto que esta deferencia hacia los profesionales de la salud es un lugar común en muchos otros sistemas. Para una lectura crítica de lo ocurrido en Inglaterra, sobre todo en cuanto a la diferencia que debe existir entre dar una opinión (médico) y establecer un hecho (juez), Lord Woolf, "Are the Courts Excessively Deferential to the Medical Profession?”, en Medical Law Review, 9, 2001, p. 11.

9 Robertson, A., "On the Function of the Law of Negligence", en Oxford Journal of Legal Studies, Vol. 33, N 1,2013 , p. 54.

${ }^{10}$ Raz (n. 1), p. 8. 
difuminó la Ley $\mathrm{N}^{\mathrm{0}} 20.584$, con su anclaje en los protocolos y las prácticas médicas, pero que puede tomarse prestada ahora para las cuestiones de hecho: ¿Existen reglas que impongan modos de comportamiento respecto de los hechos que se discuten, con independencia de si han sido legisladas o elaboradas por los jueces? ¿O el asunto queda entregado al "sentido común” de abogados y jueces? La cuestión de la normatividad de la prueba es uno de los aspectos, en mi opinión, más interesantes del análisis de la jurisprudencia chilena en materia médica.

En The Anatomy of Tort Law, Peter Cane mostró interés por este asunto de la competencia institucional para establecer las reglas de responsabilidad; es así que, a propósito de Donoghue vs. Stevenson (del deber de no dañar al prójimo o ilícito de negligencia), Cane recordó que en 1932 The House of Lords asumió como "un punto preliminar de derecho" el que la actora enfermara tras beber una botella de jengibre que había fabricado el demandado y en la que se encontraron restos descompuestos de un caracol, circunstancias que si hubiesen sido materia del juicio -sostuvo Cane- habrían supuesto considerar a las partes del caso "en su calidad de individuos y no como representantes" ${ }^{11}$. Con esto Peter Cane quería rescatar la idea de que solo cuando las partes son vistas como los representantes de una cierta clase de persona (fabricantes, consumidores, médicos) la función judicial puede participar en la evolución del derecho, algo tan central como para decir que "en este libro [The Anatomy of Tort Law] solo nos preocupamos del primer aspecto del derecho de daños, esto es, de aquellos elementos de las decisiones judiciales que conciernen a las partes en las acciones de daños, consideradas como representantes de otras [porque] las respuestas a las cuestiones de hecho "no crean precedentes"'12. En mi opinión, si por cuestiones de hecho nos referimos a lo que tiene lugar en un único momento y lugar, es cierto que se pierde interés en ocuparse de ellos desde la perspectiva del Derecho porque para eventos que son "únicos e irrepetibles" el precedente pierde utilidad como herramienta de análisis. Pero si por cuestiones de hecho aludimos a otra cosa, como me parece que es el caso en la experiencia chilena, esto es, a cuestiones de hecho como las circunstancias jurídicamente relevantes de la discusión -lo que el Derecho procesal denomina objeto procesal, y los jueces y abogados llamaron durante el siglo XX auto de prueba-, así como al modo de probar esas circunstancias, entonces la intuición de Peter Cane, en esta parte, es controvertida. En lo que sigue se demuestra que, en la justicia civil chilena referente a responsabilidad, se han entendido las cuestiones de hecho en este segundo sentido, lo que de paso le da la razón a Cane en su observación principal: solo cuando el juez trata a las partes como representantes de una determinada clase de personas (servicios de urgencia, pacientes en reposo, cirujanos plásticos) y no como individuos, es que la jurisprudencia puede regular la prueba de los hechos. Para demostrar este punto se vuelve útil distinguir las demandas por tratamiento (profesionales médicos) de las acciones que van en contra de la organización del servicio (Clínicas y Hospitales).

${ }^{11}$ Cane, P., Anatomía del derecho de daños, traducción de Arturo Carvallo y Pablo Becerra, Editorial Flandes indiano, Santiago de Chile, 2011 (1997), p. 42.

${ }^{12}$ Cane (n. 11), pp. 40-42. 


\section{Tratamiento}

Según se dijo, la distinción entre una obligación de medio ("lograr tratar") y una obligación de resultado ("lograr una meta”) ha servido de soporte técnico para dotar de contenido a los deberes de cuidado médicos. Hasta el momento, aunque la obligación principal del médico consiste en tratar de hacer lo mejor posible su trabajo (obligación de medio), ella no obsta a que algunos compromisos sean de resultado, como ocurre con la entrega de cierta información al paciente, los materiales y productos empleados en el servicio o la toma de exámenes ${ }^{13}$; el diagnóstico, según se sabe, es una obligación de medio ${ }^{14}$. En Francia, por ejemplo, el primer caso típico de responsabilidad civil derivada de una obligación de resultado en la medicina surgió con las prótesis, no por su instalación sino por la calidad del artefacto, para luego ampliarse a otros materiales usados durante el tratamiento del paciente, lo que alcanzó incluso a las enfermedades intrahospitalarias, aunque con un límite estipulado por decreto ("para satisfacer a las compañías de seguro”, observó François Chabas) ${ }^{15}$. En Chile, en cambio, la idea de un médico obligado a un resultado no irrumpió por esta vía, en donde la responsabilidad tiende a mezclarse con la protección del consumidor (lo que explicaría el trasplante de algunas excusas propias del consumo, como los riesgos del desarrollo, artículo 41 inciso $2^{\circ}$, Ley $\mathrm{N}^{\circ}$ 19.966): en la experiencia chilena se acudió a las cirugías estéticas como el escenario típico en que el médico se compromete a un resultado ${ }^{16}$, y aunque este es un supuesto acotado dentro del universo de los servicios de salud puede servir, es un ejemplo que sirve para analizar la regulación de la prueba en la responsabilidad médica.

Considérese Wagemann con Vidal, un caso en donde la paciente pactó con su médico una reducción mamaria ya que padecía de una gigantomastia bilateral. En aquel caso la Corte de Santiago descartó la responsabilidad civil del profesional por dos motivos: primero, porque consideró que su obligación era de medio, de modo que el médico "no compromete el éxito de la misma [sino que se] le exige poner a disposición del paciente su capacidad profesional y ajustar sus servicios a la lex artis" 17 y, segundo, porque decidió - vía inspección personal- que la cirugía había sido exitosa. La Corte Suprema, en cambio, revirtió esta sentencia por las razones opuestas: no solo interpretó

13 Pedrero y otro con Pinto (practicar un estudio citológico a un tejido del paciente es una obligación de resultado), C.A. Santiago, 22 septiembre 2006, Rol N ${ }^{\circ}$ 5515-2001, cons. $6^{\circ}$ (redacción del Abogado Integrante Nelson Pozo).

${ }^{14}$ Treizman y otros con Erazo y Clínica Las Condes S.A. (la paciente fue mal diagnosticada de síndrome de Pick durante cinco años, cuando adolecía de un trastorno bipolar), C.S., 5 junio 2013, Rol No 5883-2012, cons. $4^{\circ}$ (Primera Sala: redacción del Ministro Juan Araya).

${ }^{15}$ Chabas, F., “Aspectos generales de la responsabilidad médica en Francia”, en Publicaciones Doctorado en Derecho Universidad de Chile, Santiago de Chile, 2005, pp. 25-26.

${ }^{16}$ Cortes CON GARCía (se intervino a la paciente para borrar una cicatriz en su abdomen y abultarle los glúteos), C.S., 12 septiembre 2011, Rol N² 2314-2010, LegalPublishing No 54760 (Primera Sala: redacción del Abogado Integrante Jorge Medina), analizado en Pizarro, C., "Obligaciones y responsabilidad civil", en Revista Chilena de Derecho Privado, Universidad Diego Portales, N 17, 2011, pp. 241 ss.

${ }^{17}$ C.A. Santiago, 28 enero 2011, Rol No 11301-2005, cons. $9^{\circ}$ (redacción de la Ministra Rosa Maggi). 
el compromiso del profesional como una obligación de resultado, sino que decidió que la prueba rendida demostraba que la operación no había sido exitosa, por lo que casó en la forma el fallo ${ }^{18}$. En su sentencia de remplazo la Corte Suprema insistió en que la inspección personal, "como medida probatoria, permite tener por justificados los hechos observados directamente por la juez en el cuerpo de la actora” (cons. $7^{\circ}$ ). Por cierto que la Ministra Maggi y el Ministro Muñoz pudieron tener legítimas diferencias respecto del éxito o fracaso de esta cirugía, pero el punto que merece la atención es otro, y se refiere a la regulación de la prueba que contiene el considerando $7^{\circ}$ transcrito en la última nota al pie. Allí la Corte Suprema dio cuenta de las conductas que se espera que tengan lugar, especialmente por parte del propio juez de instancia, en tres de las dimensiones más relevantes de la prueba: al fijar la información relevante, en la forma de valorar esa información y al decidir los hechos probados. En efecto, (i) en cuanto a los medios de prueba, aunque existe una amplia libertad, incluso dentro de los límites que impuso el Código de Procedimiento Civil de 1903 y el Código Civil de 1855, y aunque un juez no suele ordenar explícitamente que se acuda a la mejor evidencia disponible (¿Será la inspección personal del juez la mejor forma de probar un daño estético?), la práctica demuestra que la información relevante en estos casos proviene del testimonio de los mismos profesionales de la salud: una información que suele calificarse de "suficiente" ("máxime si se considera que no existe otra prueba aportada por las demandantes en tal sentido") ${ }^{19}$ e "indispensable" para fallar el caso ${ }^{20}$; (ii) en cuanto a la valoración de las pruebas, se le ordena al juez civil que la considere tanto individualmente como en su conjunto, y que luego le asigne un peso ("otorgar mayor preeminencia" dice la Corte Suprema), un ejercicio en que se destacan las máximas de la experiencia por las que apuesta el juez, apuestas que se aproximan bastante al res ipsa loquitur ${ }^{21}$; por último,

${ }^{18}$ Para la Corte Suprema "las razones vertidas en el fallo de segundo grado no se orientan a señalar cómo se tienen por probados los hechos que se dan por asentados, sino a los motivos para tener por no justificados los hechos que basan la demanda, cuya materialidad fue percibida en forma directa y testimoniada por el juez en los antecedentes. De allí que, el desatender esa constatación, tenía por básico requerimiento el que con una prueba de igual valuación se demostrara lo contrario. En efecto, la valoración individual y comparativa del medio probatorio "inspección personal del tribunal", debió llevar a los magistrados a reconocer los hechos percibidos directamente por la señora juez que realizó la diligencia en presencia de los representantes de ambas partes, y luego han debido los jueces de la instancia, sobre la base de una ponderación conjunta de los medios de prueba, otorgar mayor preeminencia al que su análisis determine, precisando, en su caso, aquel del cual deducen los hechos y al que han otorgado mayor mérito para arribar a su convicción”, C.S., 28 enero 2011, Rol No 5849-09, cons. $7^{\circ}$ (Primera Sala: redacción del Ministro Sergio Muñoz).

19 López con Servicio de Salud Talcahuano (la paciente murió de un shock séptico), C.A. Concepción, 14 diciembre 2009, Rol N ${ }^{\circ}$ 735-2009, MJCH_MJJ22620, cons. 14º (redacción del Abogado Integrante Marcelo Villena).

${ }^{20}$ Páez y otros con Servicio de Salud Antofagasta (se discutió acerca de si el paro cardiorrespiratorio había ocurrido por la inyección de una sustancia a la que la paciente era alérgica), C.A. Antofagasta, 5 mayo 2005 , Rol No 11-2005, vLex: 30881395, cons. $3^{\circ}$ (redacción de la Ministra Laura Soto).

${ }^{21}$ Para aludir a dos casos similares a Wagemann: Hernández con Servicio de Salud de Concepción (una mamoplastia reductiva bilateral terminó en una infección intrahospitalaria de la paciente, quien sufrió una necrosis del tejido mamario y la pérdida del pezón derecho), C.S., 30 abril 2003, Gaceta Jurídica, N 274 , Rol No 1290-02, cons. $5^{\circ}$ (Tercera Sala: redacción del Abogado Integrante Roberto Jacob); la necrosis provocó 
(iii) en cuanto al juicio de hecho propiamente tal, se autoriza el empleo de la convicción del juez para decidir los hechos probados, decisión que no será revisada por las Cortes salvo infracción de lo que la jurisprudencia llama leyes reguladoras de la prueba. Esta es la soberanía judicial para decidir los hechos.

Estas reglas, por supuesto, no cambian si la cirugía plástica pasa a ser entendida como una obligación de medio; ${ }^{22}$ entonces habría una alteración en la carga de la prueba, como se verá en la segunda parte, pero la regla de la carga de la prueba mantendría su calidad de ley reguladora. Y, más aún, esta regulación judicial de las cuestiones de hecho no es endémica solo en los casos de cirugía plástica o de medicina satisfactiva, sino que también lo es en la medicina curativa, y se aplica igualmente en los juicios en contra de Clínicas y Hospitales por la organización del servicio.

\section{Organización}

A mediados de los años noventa, Pedro Zelaya puso de manifiesto que la responsabilidad de los Hospitales y Clínicas por los daños causados a un paciente se justifica en el control que estas entidades ejercen en la prestación de los servicios médicos ${ }^{23}$. Así lo refleja, por ejemplo, el Reglamento de Hospitales y Clínicas vigente desde $1982^{24}$. Algo característico de los deberes que rodean a la organización es que se atiende más al costo del servicio y menos a los dictados de la propia medicina, lo que ya arroja una pista acerca de las cuestiones de hecho que deberán ser tomadas en cuenta para la prueba ${ }^{25}$. En el caso chileno la responsabilidad por la organización muestra dos claras tendencias: por un lado, el contenido de los deberes de cuidado es sensible a ciertos hechos que incrementan los riesgos (por ejemplo, las atenciones de urgencia o una condición objetiva del paciente que era conocida por el servicio); por el otro, el empleo de una regla de entrada (llámese culpa organizacional, dependiente anónimo o teoría del órgano) que autoriza al juez a inferir de ciertos hechos la responsabilidad por los daños.

la pérdida de ambos pezones, C.S., 26 septiembre 2006, Rol N 1968-2006 (Tercera Sala: redacción del Abogado Integrante Hernán Álvarez).

${ }^{22}$ Yeber con Escobar (practicar una rinoplastia implica una obligación de medio), C.A. Chillán, 22 abril 2009, Rol No 158-2007, vLex: 332897030, cons. 11º (redacción del Ministro Darío Silva).

${ }^{23}$ Esta responsabilidad puede expresarse en la negligencia al elegir o vigilar al funcionario, en una responsabilidad vicaria o en el riesgo creado, Zelaya, P., "Responsabilidad civil de hospitales y clínicas (modernas tendencias jurisprudenciales)", en Revista de Derecho, Universidad de Concepción, No 201, 1997, pp. 30-36.

${ }^{24}$ Art. 19 inciso $1^{\circ}$, DS N 161 (Ministerio de Salud, 19 de septiembre de 1982): "El Director será responsable de todos los aspectos técnicos de la gestión del establecimiento y deberá velar por el adecuado funcionamiento de los equipos, instrumentos e instalaciones necesarias para la correcta atención de los pacientes, así como por la observancia de las normas y procedimientos respectivos, por parte de la dotación del establecimiento".

${ }^{25}$ En Inglaterra, por ejemplo, tras la reforma al National Health Service en los años noventa, de debatió intensamente sobre el contenido de los deberes de cuidado en la organización y cómo ellos incidían en la distribución final de los recursos públicos, Beswick, J., "Commentary. A First Class Service? Setting the Standard of Care for the Contemporary NHS. Garcia v. St. Mary's NHS Trust [2006] E.W.H.C. 2314 (QBD)”, en Medical Law Review, 15, 2007, pp. 245-252. 
2.1. En cuanto a lo primero, los deberes de cuidado de los Hospitales y Clínicas dependen de las funciones que desarrollan y los fines que sirven. Por ello es que suele fallarse que "para establecer la falta de servicio debe tenerse en cuenta la finalidad u objetivo asignado al órgano en su creación y la realidad jurídica, económica y social con la que actúa el servicio" 26 . En términos más concretos, el tipo de servicio que se brinda y ciertos rasgos conocidos del paciente inciden en el cuidado debido: así, la Corte Suprema ha resuelto que "tratándose de actividades que presentan dificultades particulares de funcionamiento, como ocurre con los establecimientos hospitalarios de urgencia, es necesaria la existencia de una falta grave" ${ }^{27}$, y la Corte de Valparaíso, en el caso de un menor de dos meses que murió por un virus sincicial y adenovirus que contrajo en el Hospital, decidió que "el protocolo de atención de las personas con Síndrome de Down, en todo servicio hospitalario, más aún para el presente caso en que estamos en presencia de un lactante de seis meses de edad, debiera contener una atención preferencial, diligente y específica, más tratándose de personas que poseen un sistema inmunológico disminuido, que provoca enfermedades respiratorias severamente riesgosas" 28 . ¿Y qué ocurrirá en un caso intermedio, como el de un servicio médico de urgencia pediátrica? Parece que allí prevalecería este segundo aspecto por sobre el primero ${ }^{29}$. Otras aplicaciones de la misma idea, especialmente respecto del servicio que ofrecen los Hospitales, son la atención oftalmológica los fines de semana ${ }^{30}$, los planes de vigilancia epidemiológica en contra del tétano ${ }^{31}$, la presencia en pabellón de por lo menos un médico al momento de recibir al paciente ${ }^{32}$ y el

${ }^{26}$ Jara con Hospital Regional de Concepción, C.A. Concepción, 3 agosto 2009, Rol N ${ }^{\circ}$ 1499-2008, MJCH_MJJ21005, cons. $10^{\circ}$ (redacción del Ministro Juan Villa). La Corte de Concepción acudió, ese mismo día, a la "finalidad institucional" del servicio, en Estrada con Servicio de Salud Concepción, C.A. Concepción, 3 agosto 2009, Rol N 1569-08, citado en Cárdenas, H. y Moreno, J., Responsabilidad médica. Estándares jurisprudenciales de la falta de servicio, Thomson Reuters, Santiago de Chile, 2011, p. 69. Este último fallo sería confirmado por la Corte Suprema (29 diciembre 2009, Rol No 7043-2009).

${ }^{27}$ Vega y otro con Servicio de Salud Araucanía Sur, C.S., 12 septiembre 2007, Rol No 3222-2006, cons. $4^{\circ}$ (Tercera Sala: redacción del Ministro Adalis Oyarzún; voto en contra de los Ministros Héctor Carreño y Pedro Pierry).

${ }^{28}$ Jara y otra con Servicio de Salud Aconcagua, C.A. Valparaíso, 11 junio 2009, Rol No 347-2009, vLex: 58790862 , con. $6^{\circ}$ (redacción del Ministro Alejandro García).

${ }^{29}$ Berríos con Bentjerodt, Sallés y Pontificia Universidad Católica de Chile (la ausencia de un radiólogo durante la noche, que habría permitido detectar la neumonía aguda de la niña, supone una "falencia de organización y coordinación en la operatividad del establecimiento”, que genera responsabilidad por la muerte), C.A. Santiago, 5 junio 2001, Rol N $36518-1998$, cons. $57^{\circ}$ y $58^{\circ}$ (redacción del Ministro Carlos Cerda).

${ }^{30}$ Villamán con Tizando y Servicio de Salud Bio-Bio (un paciente perdió su ojo al no ser asistido en el Hospital de Los Ángeles), C.A. Concepción, 27 mayo 2009, Rol No 917-2007, vLex: 332732702, cons. $9^{\circ}$ (redacción del Ministro Jaime Solís).

${ }^{31}$ Carrasco y otros con Servicio de Salud de Osorno (un hombre de cuarenta años cayó de la moto que conducía por un camino rural y falleció porque la herida en su rodilla izquierda se infectó con tétano), Primer Juzgado de Letras de Osorno, 12 septiembre 2011, Rol N²587-2009, cons. $13^{\circ}$ (redacción del Juez Raúl Ramírez).

32 Silva con Pereira y Servicio de Salud Atacama, C.A. Copiapó, 28 junio 2002, Gaceta Jurídica, No 268, Rol N $82544-2002$, cons. 1 (redacción de la Ministra Luisa López). 
cuidado que se le debe a un recién nacido ${ }^{33}$. Para efectos de la prueba, entonces, son decisiones normativas de este tipo las que finalmente dirimen el cuidado debido y, con ello, fijan los hechos jurídicamente relevantes del caso, hechos acerca de los que se rendirá la prueba.

2.2. En cuanto a lo segundo, los Hospitales y Clínicas son responsables de los daños que ocurren en su interior porque allí "se realizan procedimientos, tratamientos y operaciones que pueden afectar directamente la salud de las personas" 34 , es decir, por el control que ejercen sobre las prestaciones médicas o una parte relevante de ellas. Así, por ejemplo, la organización es responsable por los defectos en los instrumentos que se emplean, como un desfibrilador que no sirve en un paro respiratorio ${ }^{35}$ o una red de oxígeno en mal estado ${ }^{36}$, por el mayor cuidado que precisan algunos pacientes, como quienes han ingresado por un riesgo conocido de cometer suicidio ${ }^{37}$, y del daño que sufren quienes guardan reposo en una sala, ya sea después de un embarazo ${ }^{38}$ o de haber sido anestesiados ${ }^{39}$. La responsabili-

${ }^{33}$ Coria con Sociedad Cortés y Aguilera y Cía. Ltda. (Clínica Juan Pablo II) (el recién nacido falleció de un paro cardiorrespiratorio), C.A. Santiago, 10 julio 2002, Revista de Derecho y Jurisprudencia, Tomo XCIX, sec. $2^{a}$, p. 90 , cons. $23^{\circ}$ (redacción de la Abogada Integrante Ángela Radovic).

${ }^{34}$ López con Cooper y otro (el paciente quedó con un trozo de aguja alojado en su hombro luego de la operación), C.A. Valparaíso, 11 octubre 2011, Rol No 1285-2011, MJCH_MJJ29694, cons. $3^{\circ}$ (redacción del Ministro Jaime Arancibia). En esta misma línea, Aburto con Clínica Cordillera S.A. (el menor falleció mientras se encontraba hospitalizado en la Clínica), C.A. Santiago, 3 enero 1997, Rol N 1010-1996, Gaceta Jurídica, $\mathrm{N}^{\circ} 199$, p. 89 , cons. $2^{\circ}$.

${ }^{35}$ Rodríguez y otros con Servicio de Salud Concepción: C.A. Concepción, 15 noviembre 2010, Rol No 378 2010, MJCH_MJJ25596, cons. 5º (redacción del Ministro Diego Simpértigue).

${ }^{36}$ Riquelme con Hospital San José (la paciente murió por el mal funcionamiento de la red de oxígeno del Hospital), C.A. Santiago, 18 enero 2011, Rol No 8573-2009, MJCH_MJJ26022, cons. $7^{\circ}$ (redacción del Abogado Integrante Francisco Tapia; voto en contra del Ministro Juan Escobar).

${ }^{37}$ En este sentido, Urra con Fisco de Chile (la paciente se suicidó dentro del Servicio de Psiquiatría del Hospital Naval de Viña del Mar, con un cordón de su pantalón, el que no había sido advertido por los enfermeros), C.A. Valparaíso, 16 octubre 2007, Rol No 45-2007, cons. $4^{\circ}$ (redacción del Ministro Julio Torres); Ebner y otro con Servicio de Salud Aysén (una adolescente embarazada, con un diagnóstico de esquizofrenia, se suicidó en el área de maternidad del Hospital, cuyo lugar para la atención de pacientes con problemas de salud mental no disponía de suficientes camas), C.A. Coyhaique, 30 diciembre 2009, Rol N 101-2009, MJCH_MJJ22471, cons. $3^{\circ}$ (redacción del Ministro Gustavo Vásquez); Medel con Servicio de Salud Aconcagua (el paciente se arrojó desde la ventana del comedor, en un tercer piso, esta no contaba con ningún tipo de vigilancia), C.A. Valparaíso, 15 junio 2005, Rol No 917-2003, LegalPublishing: CL/JUR/6590/2005, cons. $3^{\circ}$ (redacción del Ministro Julio Torres); V. con $R$. (se estableció la responsabilidad penal del médico respecto del suicidio de una paciente que ya había intentado suicidarse antes, en dos ocasiones), C.A. Santiago, 22 agosto 1983, Gaceta Jurídica, No 39, Rol No 2096-1982, cons. 12 (redacción del Ministro Mario Garrido). En este último caso la Corte de Santiago resolvió que la decisión de los padres de internar en un establecimiento de salud a una hija que ha intentado suicidarse no implica exponerla al riesgo de que se suicide en ese lugar (cons. $\left.17^{\circ}\right)$.

${ }^{38}$ García con Servicio de Salud Viña del Mar (una paciente de veintisiete años murió debido a una tardía detección de la metrorragia que sufrió tras su cesárea), C.S., 17 octubre 2012, Rol Nº 6723-2012 (Tercera Sala: redacción del Ministro Pedro Pierry).

39 En esta línea, Donoso y otro con Núñez y Servicio de Salud Libertador Bernardo O'Higgins (la paciente falleció de un paro cardiorrespiratorio), C.A. Rancagua 27 agosto 2008, Rol N 403-2007 (redacción del Ministro Ricardo Pairacán); Bravo con Ortega y Servicio de Salud Central (se decidió que el médico era responsable 
dad de la organización incluye el desempeño de sus dependientes en sus diversas labores, por ejemplo, por "la perfecta identificación y localización de todas las sustancias o medicamentos que se deben usar en una intervención quirúrgica” ${ }^{40}$.

Lo anterior se mantiene incluso cuando el paciente ha suscrito un acuerdo en la modalidad de libre elección (Art. 143, DFL N ${ }^{\circ} 1$ del Ministerio de Salud, 2006) para escoger al profesional o al establecimiento encargado del servicio. Así, por ejemplo, la jurisprudencia ha fallado que "no puede deducirse que el mismo [acuerdo] exonere al Hospital del deber de cuidado y vigilancia de un paciente psiquiátrico ingresado a pensionado, ni de prestar los servicios de vigilancia inherentes al estado de un enfermo que precisamente se interna para evitar que sus inclinaciones suicidas acaben con su vida" ${ }^{1}$. Como la responsabilidad deriva en buena medida del control que se ejerce sobre las prestaciones médicas, los organismos que no forman parte del sistema de salud pero que brindan servicios médicos también son responsables, como es el caso de Gendarmería de Chile ${ }^{42}$. Y, en sentido inverso, es la ausencia de este control lo que exime a las Isapres ("instituciones" de salud previsional) de responder por los daños del paciente ${ }^{43}$, salvo en ciertos casos, como el de una Isapre que incorpora en su lista de médicos a un falso profesional $^{44}$. Algo similar ocurre con los laboratorios, que pueden ser responsables en algunos supuestos, como los de sangre contaminada ${ }^{45}$.

Esta segunda tendencia jurisprudencial indica que en todos estos asuntos "los perjudicados no requieren individualizar ni perseguir al funcionario cuya acción personal

penalmente por el daño cerebral que sufrió la paciente), C.S., 4 octubre 1984, Rol N 23634, Revista de Derecho y Jurisprudencia, Tomo LXXXI, sec. $4^{\mathrm{a}}$, p. 212, cons. $10^{\circ}$ (redacción del Ministro José Eyzaguirre; voto en contra del Ministro Israel Bórquez y del Abogado Integrante Enrique Urrutia).

40 Tala con Clínica Las Condes S.A. (la pabellonera del lugar irrigó la vejiga del paciente con cloruro de sodio), C.A. Santiago, 28 enero 1993, Gaceta Jurídica, No 151, Rol No 2020-1992, cons. $8^{\circ}$ (redacción del Ministro Víctor Montiglio); Pérez y otro con Servicio de Salud Metropolitano Sur (la paciente murió en el Hospital de Buin, cuyo personal no impidió que ingiriese un fármaco inadecuado), C.S., 18 enero 2006 , Rol No 4277-2005, MJCH_MJJ10591 (Tercera Sala: redacción del Abogado Integrante Manuel Daniel).

41 Torres y otros con Servicio de Salud Valparaíso-San Antonio, C.A. Valparaíso, 4 abril 2006, Rol N $704-$ 2005, vLex: 30888638, cons. $4^{\circ}$ (redacción del Abogado Integrante Bernardino Muñoz).

${ }^{4}$ En este sentido, Herrera con Fisco de Chile (al interno se le tuvo que amputar una pierna en su tratamiento contra el cáncer), C.A. Santiago, 29 noviembre 2011, Rol No 454-2009, vLex: 339910782, cons. $6^{\circ}$ (redacción del Ministro Cornelio Villarroel); Bobadilla y otros con Fisco de Chile (el recluso falleció de una meningitis que le fue diagnosticada de forma tardía), C.A. Valparaíso, 18 diciembre 2006, Rol N ${ }^{\circ} 2828$ 2005, cons. $12^{\circ}$ (redacción del Abogado Integrante Carlos Müller).

43 Así, por ejemplo, en Henríquez y otro con Andrade e Isapre Río Blanco Ltda. (una paciente que tenía retardo mental y padecía un cáncer de tiroides sufrió complicaciones luego de que el dentista le extrajera varias piezas dentales), C.A. Valparaíso, 9 mayo 2007, Rol Nº 951-2006, vLex: 30864668, cons. $9^{\circ}$ (redacción del Ministro Rafael Lobos); Valenzuela con Isapre Colmena Golden Cross S. A. y Servicios Odontológicos Ltda. (una paciente de doce años sufrió complicaciones tras la extracción de sus frenillos), C.A. Santiago, 9 junio 2008 , Rol N $1148-2003$, vLex: 329631815, cons. $16^{\circ}$ (redacción de la Ministra Rosa Maggi).

${ }^{4}$ Martínez con Salazar e Isapre Banmédica (la responsabilidad de la empresa de seguros de salud fue simplemente conjunta), C.A. Santiago, 23 octubre 1991, Revista de Derecho y Jurisprudencia, Tomo LXXXVIII, sec. $4^{\circ}$, p. 160 , cons. $2^{\circ}$ y $4^{\circ}$ (redacción del Abogado Integrante Franklin Geldres).

45 Avendaño con Clínica Portales y Sociedad Kohan Hermanos Limitada, C.A. Santiago, 28 abril 2000, Gaceta Jurídica, No 238, Rol No 6956-1996, cons. $5^{\circ}$. 
origina la falta" 46 . En efecto, nuestra Corte Suprema ha resuelto que "basta probar que alguien dentro de la organización hospitalaria incurrió en culpa" ${ }^{47}$, incluso aunque no pueda identificarse la calidad en que actuó: puede haber sido un funcionario del Servicio ${ }^{48}$ o no ${ }^{49}$, debido a que "la conducta del funcionario no se imputa a su persona, sino a la función pública que ejecuta" ${ }^{50}$. En el caso del trabajo en equipo, la misma Corte Suprema ha resuelto que la responsabilidad deriva de que "todos participan con sus particulares y parciales actos a la realización del fin común”; de allí que una médico respondiera, incluso penalmente, por la muerte de un menor atendido por una leucemia linfoblástica aguda tras inyectarlo con una jeringa que fue mal preparada por la enfermera ${ }^{51}$.

En definitiva, cuando se trata de quienes organizan las prestaciones médicas la experiencia chilena enseña que el actor no tiene que esforzarse en la prueba de ciertos aspectos, como el identificar al funcionario que provocó el daño o la calidad en que intervino en el acto, aunque esta faceta haya sido excepcionalmente usada por los tribunales para descartar la responsabilidad ${ }^{52}$. Desde el punto de vista de la prueba, lo razonable es que el Hospital o la Clínica se encuentren en una mejor posición para informarle al

46 Torres y otros con Servicio de Salud Talcabuano, C.A. Concepción, 18 diciembre 2003, Rol No $1703-$ 2003, vLex: 30938570, cons. 6 (redacción de la Ministra Silvia Oneto); también en Revista de Derecho y Jurisprudencia, Tomo CII, sec. $5^{\mathrm{a}}$.

47 Fierro con Servicio de Salud Talcabuano, C.S., 24 enero 2002, Rol No 1977-1999, Gaceta Jurídica $\mathrm{N}^{\circ} 259$, cons. $6^{\circ}$ (redacción del Ministro Eliseo Araya).

${ }^{48}$ Llanca con Fisco de Chile (una paciente con un diagnóstico de quiste ovárico izquierdo sufrió graves quemaduras en la zona vulvar debido al lavado genital que le hizo, antes de la cirugía, una matrona dependiente del Hospital Naval), C.S., 4 septiembre 2012, Rol No 8044-2010, MJCH_MJJ33047 (Tercera Sala: redacción del Ministro Juan Escobar).

49 Torres con Servicio de Salud Concepción (el caso de un menor que murió durante un tratamiento endovenoso en donde la médico que intervino no era funcionaria del Hospital pero "servía o trabajaba de hecho bajo las órdenes de la dirección de dicho establecimiento”), C.S., 13 enero 2011, Rol N 6665-2008, cons. $5^{\circ}$ (Tercera Sala: redacción del Abogado Integrante Luis Bates).

50 Andrade con Servicio de Salud Puerto Montt, C.S., 23 diciembre 2009, Rol No 3115-2008, cons. $15^{\circ}$ (Tercera Sala: redacción del Abogado Integrante Guillermo Ruiz).

51 T. y M. con Rabanal y Celis, C.S., 16 junio 2009, Rol No 5076-08, MJCH_MJJ20294, cons. $6^{\circ}$ (Segunda Sala: redacción del Ministro Hugo Dolmestch). La confianza es un elemento clave para establecer la responsabilidad en los trabajos en equipo, Puppe, I., "División del trabajo y de la responsabilidad en la actuación médica”, traducción de Nuria Pastor, en InDret, Barcelona, 4, 2006, pp. 3-5; el paciente no suele participar de la composición del equipo médico, sino que ese arreglo descansa en la confianza entre los profesionales o en una medida que toma la propia organización, Pizarro, C., "La responsabilidad civil médica por el hecho ajeno", en Revista Chilena de Derecho Privado, Universidad Diego Portales, No 1, 2003, pp. 192-193.

52 Así, por ejemplo, Pastor con Goñi y Hospital Clínico de la Pontificia Universidad Católica (una cirugía terminó en una parálisis facial de la paciente debido a un tumor alojado en un nervio facial). La Corte de Santiago descartó la responsabilidad del Hospital porque "no está probado que esa entidad haya tenido injerencia alguna en la elección del médico y en el equipo de médicos o personal sanitario que participó en la cirugía; y los documentos agregados en esta instancia no resultan aptos para arribar a la conclusión de que el demandado prestó sus servicios en régimen de dependencia con una entidad hospitalaria, lo que supone que el paciente acude al centro médico, quien le designa un facultativo concreto que lo atiende", C.A. Santiago, 6 agosto 2009, Rol No 10569-2005, MJCH_MJJ20562, cons. $14^{\circ}$ (redacción del Abogado Integrante Emilio Pfeffer). 
tribunal acerca de esas circunstancias, así como del estado de salud del paciente por medio de su ficha clínica ${ }^{53}$, un documento al que el paciente ha tenido derecho desde antes de la Ley $\mathrm{N}^{\mathrm{0}} 20.584^{54}$, pero fue esta última ley la que reconoció, además, el derecho del paciente a exigir "un informe legible" de los principales aspectos del tratamiento recibido (Art. 11). En mi opinión, la jurisprudencia que se acaba de citar demuestra el primer punto de este trabajo: los hechos jurídicamente relevantes del caso-objeto procesal, auto de prueba, puntos de prueba- dependen de los márgenes de cuidado debido, cuidado que a su vez depende de ciertos criterios normativos que son informados por la ley, los protocolos médicos y la propia jurisprudencia. El conocimiento de estos criterios por parte de la comunidad de jueces y abogados permite que las cuestiones de hecho no sean un misterio que se devela solo con la lectura de la sentencia definitiva, sino que algo que se puede anticipar, al menos en varios de sus flancos relevantes. Y lo mismo ocurre con las reglas de salida de la responsabilidad, que en el caso médico no suele ser ni la prescripción ${ }^{55}$, ni tampoco la diligencia del demandado, sino la causalidad.

\subsection{Causalidad como salida}

Los riesgos, errores e incertidumbre que rodean a los juicios de responsabilidad médica suelen expresarse en términos de prueba de la causalidad. Para los casos más simples, como una atención de urgencia por heridas cortopunzantes proferidas por un tercero en que el paciente muere a causa de esa agresión ${ }^{56}$, es razonable descartar

${ }^{53}$ El Reglamento de Hospitales y Clínicas contempló un sistema de registro y bioestadística de todos los pacientes, este debe conservarse por un lapso mínimo de diez años, así como el derecho de los pacientes a "recabar la entrega de informes de resultados de exámenes de laboratorio, de anatomía patológica, radiografías, procedimientos, diagnósticos y terapéuticos (cirugías, endoscopias y otros), en el momento que lo estime necesario y dentro del plazo mínimo establecido" (Art. 17). Si bien esta es una información reservada, debe ser entregada al juez que la requiera (Art. 22). Por su parte, la Ley $\mathrm{N}^{\circ} 20.584$ definió la ficha clínica como "el instrumento obligatorio en el que se registra el conjunto de antecedentes relativos a las diferentes áreas relacionadas con la salud de las personas” y la calificó como un dato sensible (Art. 12); los prestadores deben guardar esta ficha por un plazo de quince años y entregar una copia de ella, total o parcial, al tribunal que la requiera "siempre que la información contenida en la ficha clínica se relacione con las causas que estuvieren conociendo" (Art. 13, letra C).

${ }^{54}$ Rezzio con Director Clínico de la Universidad Católica (una paciente en tratamiento por un cáncer se infectó con Staphylococcus aureus cuando se le instaló un catéter), C.A. Santiago, 30 octubre 1997, Rol N $3645-$ 1997, Revista de Derecho y Jurisprudencia, Tomo XCIV, sec. 5a , p. 241. La Corte de Santiago acogió el recurso de protección en el entendido de que negar el acceso a la ficha clínica compromete el derecho a la salud y a la integridad física y psíquica del paciente.

55 Por ejemplo, Patesi con Zambrano (se le colocó yeso en la muñeca al paciente sin haberle hecho una reducción previa, lo que le provocó una deformación ósea y serios problemas en su articulación), C.A. Santiago, 10 octubre 2000, Gaceta Jurídica, No 245, Rol No 32988-1998 (redacción del Abogado Integrante Francisco Merino).

${ }^{56}$ En esta línea, Franchini con Servicio de Salud Valdivia (un hombre murió tras ingresar de urgencia al Hospital con heridas cortopunzantes en su tórax que afectaban su vena cava), C.S., 26 junio 2008 , Rol No 5667-06, MJCH_MJJ17475, cons. $11^{\circ}$ (Tercera Sala: redacción del Ministro Pedro Pierry); Godoy con Berger y Lobos, C.A. Punta Arenas, 29 mayo 2009, Rol No 23-2007, MJCH_MJJ10116, cons. $3^{\circ}$ (redacción de la Ministra Virginia Bravo). 
las demandas en contra de Hospitales o Clínicas sobre la base de la causalidad. Así lo sugiere, sin ninguna ironía, la navaja de Occam. Pero lo que llama la atención es el profuso empleo de la causalidad como una regla de salida en casos que no son fáciles ${ }^{57}$, incluidos aquellos en que la obligación del médico era de resultado ${ }^{58}$ y otros en que el historial clínico del paciente aportaba una prueba favorable al demandante ${ }^{59}$. Con diferentes fórmulas ("[no se demostró que el daño derive] única y exclusivamente por un mal funcionamiento del Servicio" 60 , "no se determinó en forma indubitada cuál fue [su] causa precisa” $)^{61}$, los jueces usan la causalidad para decidir que no se trató de un caso de responsabilidad, sino de un infortunio.

Por cierto que este punto requiere de un estudio más detenido acerca del error médico, el riesgo terapéutico y el valor de la prueba estadística, pero de este análisis es posible concluir que, al menos durante los últimos veinte años en Chile, la causalidad ha servido para evitar la responsabilidad tanto en casos de tratamiento médico (véase el caso de un hijo que falleció por un traumatismo craneoencefálico tras emplearse fórceps durante la cesárea) ${ }^{62}$ como por la organización del servicio (véase el caso de trece menores en tratamiento oncológico en un lugar que no tenía autorización sanitaria y que

${ }^{57}$ A modo de ejemplos, Garmendia con Behm (una paciente que se sometió a una liposucción sufrió tres días después de queloides, esto es, de una cicatrización enferma de la piel), C.A. Santiago, 30 junio 2006 , Rol No 3378-2002, vLex: 32027444, cons. $9^{\circ}$ (voto en contra del Abogado Integrante Benito Mauriz); Muñoz con Servicio de Salud Concepción (una paciente que sufría intensos dolores de estómago fue diagnosticada de deshidratación, pero luego acudió a una Clínica en donde se le diagnosticó diverticulitis aguda, que fue la causa de su muerte), C.A. Concepción, 16 diciembre 2009, Rol N 10-2009, vLex: 242791194, cons. $14^{\circ}$ (redacción del Ministro Claudio Gutiérrez); Baeza y otro con Servicio de Salud Arauco (no se detectó la apendicitis del menor, quien luego falleció de una peritonitis), C.A. Concepción, 28 octubre 2008, Rol No 2558-2005, cons. $15^{\circ}$ (redacción del Ministro Guillermo Silva); Parra y otros con Servicio de Salud Viña del Mar (muerte del paciente), C.S., 14 octubre 2009, Rol No 2345-2008, cons. $7^{\circ}$ (Tercera Sala: redacción de la Ministra Sonia Araneda); Delgado y Torres con Pontificia Universidad Católica de Chile y otros (una estudiante de quince años falleció durante un tratamiento por leucemia, lo que sus padres atribuyeron al inadecuado monitoreo de los médicos que no detectaron la pancreatitis aguda que causó su muerte), C.S., 13 agosto 2012, Rol N ${ }^{\circ} 582$ 2011, cons. $8^{\circ}$ (Primera Sala: redacción del Ministro Carlos Cerda).

58 Medina con García (una cirugía para eliminar unas mamas axilares y reducir el volumen de los senos generó molestias en la paciente y requirió de una segunda intervención), C.A. Valparaíso, 8 noviembre 2011,

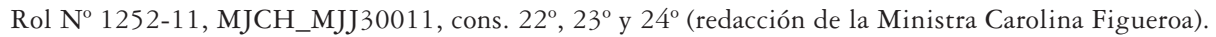

59 Miranda con Vergara (según su ficha, la paciente adolecía de obesidad mórbida y de una artrosis de cadera), C.A. Arica, 15 octubre 2010, Rol N 271-2010, MJCH_MJJ25138, cons. $8^{\circ}$ (redacción del Ministro Rodrigo Olavarría).

${ }^{60}$ Hidalgo y otros con Servicio de Salud Valparaíso-San Antonio y otros (un paciente de veintisiete años fue operado de urgencia por una apendicitis aguda y en los días siguientes sufrió dolor abdominal, fiebre y vómitos, falleciendo un par de semanas después por un shock séptico), C.S., 14 octubre 2008, Rol N 1976 2007, vLex: 332896090, cons. $7^{\circ}$ (Tercera Sala: redacción del Ministro Pedro Pierry).

${ }^{61}$ Concha y Vera con Servicio de Salud Concepción (muerte de un menor), C.S., 28 marzo 2007, Rol N $3611-$ 2006, MJCH_MJJ9471, cons. $2^{\circ}$ (Tercera Sala: redacción del Ministro Pedro Pierry).

${ }^{62}$ Chain con Figueroa, C.A. Santiago, 31 julio 1991, Gaceta Jurídica, N ${ }^{\circ} 133$, cons. $10^{\circ}$ (redacción del Ministro Juan González); también en Revista de Derecho y Jurisprudencia, Tomo LXXXVIII, sec. $4^{\mathrm{a}}$. 
fueron contagiados con el virus de la hepatitis $\mathrm{B})^{63}$. Pienso que, desde el punto de vista de la prueba, son dos los factores que promueven esta práctica: un notable influjo de la justicia penal y sus peculiares exigencias probatorias (nótese que en los dos ejemplos de los paréntesis lo que se debatió fue la responsabilidad penal del médico) ${ }^{64}$ y la soberanía judicial. Esto se hace explícito cuando el juez comunica los hechos que motivan su sentencia, una instancia a la que llega luego de recorrer varios tramos que la justicia chilena ha regulado para los casos de responsabilidad civil médica: el testimonio de los expertos, las máximas de la experiencia, la carga probatoria y el estándar de prueba. Esta segunda parte del trabajo examina las reglas que guían cada uno de esos aspectos.

\section{Ciencia y EXPERIENCIA}

En Rabie con Home Medical Clinic Chile S.A. (Help) y Veiga, un hombre mayor llamó en la madrugada a Help porque le dolía el pecho y el cuello, síntomas que en el servicio ("de rescate médico") atribuyeron a una gripe, aconsejándole que comprara ciertos medicamentos. Pero el malestar continuó, de modo que unas horas más tarde el mismo hombre le pidió a Help que enviase a su casa a un médico, quien también se inclinaría por la hipótesis de una gripe. El origen de su malestar solo se develaría al amanecer cuando fue internado en una Clínica por un infarto agudo al miocardio. En Rabie, los jueces de instancia negaron que los demandados - la empresa y la médico- fuesen responsables de los daños, en una decisión que la Corte Suprema se negó a revisar esgrimiendo la soberanía judicial, o sea, que el juez de instancia tiene competencia exclusiva para establecer los hechos probados, salvo que infrinja las leyes reguladoras de la prueba, esto es, que no respete ciertas "normas básicas de juzgamiento, que contienen deberes, limitaciones o prohibiciones a que deben sujetarse los sentenciadores" 65 .

El modo en que la jurisprudencia civil chilena ha normativizado la prueba en la responsabilidad médica debiese ser claro a estas alturas. La soberanía judicial hace del juicio de hecho (= decidir las circunstancias cuya calificación jurídica hará del caso uno de responsabilidad o uno de infortunio) una tarea exclusiva del juez de instancia, tanto al definir los hechos que deben probarse (objeto procesal o auto de prueba) como los hechos probados (estándar de prueba). Para cumplir con esto el juez debe atribuirle peso a la información, luego de haberla valorado tanto individualmente como en su conjunto (recuérdese lo dicho en Wagemann). Si bien existe una amplia libertad en cuanto a la

${ }^{63}$ Álvarez y otro con Quintana y otro, C.S., 19 enero 2012, Rol No 7086-2009 (Segunda Sala: redacción del Ministro Carlos Künsemüller; voto en contra del Ministro Jaime Rodríguez).

${ }^{64}$ En la misma línea, Camus con Villalobos y Cornejo (la paciente falleció de una peritonitis bacteriana provocada por un problema en el instrumento con que se le practicó una histerectomía laparoscópica, pero se descartó la responsabilidad penal), C.A. Copiapó, 25 marzo 2002, Gaceta Jurídica, N ${ }^{\circ}$ 265, cons. $9^{\circ}$ (redacción de la Ministra Luisa López).

65 C.S., 24 abril 2007, Rol No 3886-2005, vLex: 332775406, cons. $4^{\circ}$ (redacción de la Ministra Margarita Herreros). 
información admisible, los jueces tienden a decidir sobre la base de la mejor evidencia disponible, la que en estos casos emana de los mismos profesionales de la salud cuando declaran sobre temas como la ficha clínica del paciente, el protocolo aplicable o la corrección de las decisiones que se tomaron. Este juicio de hecho, en principio, no es controlado por la Corte Suprema: "La apreciación comparativa de dos o más medios de prueba que resulten contradictorios [es] parte de un marco normativo en que los jueces de mérito pueden hacer uso de una facultad privativa de comparación de la prueba rendida en el proceso, correspondiendo tal actuación a un proceso racional del tribunal no sujeto al control del recurso de casación en el fondo" (Rabie con Home Medical Clinic Chile S.A. (Help\} y Veiga, cons. $5^{\circ}$ ).

El juicio de hecho, como se anticipó, solo será revisado por la Corte Suprema cuando no se cumpla con alguna de las leyes reguladoras de la prueba ${ }^{66}$. Para nuestra jurisprudencia estas leyes son normas imperativas, no permisivas; esto es, en principio ninguna de ellas se inmiscuye en la valoración judicial de la prueba (que es siempre "libre") ${ }^{67}$, sino que regulan otros aspectos de la prueba, como la información que es admisible, la carga de aportar esa información y, en algunas ocasiones, el peso que le corresponde a una evidencia. Es dentro de este marco normativo que deben explorarse los alcances de la declaración de los médicos - una singular mezcla de prueba testimonial y pericial-, las máximas de la experiencia -como formas de pesar la información-, la carga de la prueba -como una regla de suministro de datos- y los estándares de prueba -con la incipiente pugna entre la convicción judicial y el res ipsa loquitur-.

\section{Expertos como testigos}

Dos rasgos que destacan en el testimonio experto como medio de prueba en la responsabilidad médica son, en cuanto a su admisibilidad, una amplia regla inclusiva, basada en dos estrategias: una confianza en la imparcialidad de los profesionales y la necesidad de su relato para los no expertos; junto a la posibilidad de corregir aquella amplitud en la regla de admisibilidad por medio de dos vías: a base del peligro de un acuerdo corporativo (o "conspiración del silencio") y mediante la prueba ilícita. En

${ }^{66}$ Pero incluso en este punto la Corte Suprema se muestra reticente a revisar la decisión del juez, porque considera que "inferir la causalidad" ("inferir la negligencia” o "inferir la responsabilidad") supone una calificación jurídica -o sea, es algo "de derecho", no "de hecho"-, de modo que un recurso de casación fundado en una infracción a las leyes reguladoras de la prueba (típicamente por el peso asignado a la declaración del experto) no sería adecuado para revisar esa calificación. En otras palabras, lo que hace la Corte Suprema es restringir ella misma su competencia sobre la base de que "la responsabilidad no se prueba", en algo que es propio de una distinción rígida entre hecho y derecho como se advertía al comienzo del trabajo. Así ocurrió, por ejemplo, en Carrasco y otros con Servicio de Salud Metropolitano Oriente (un ciclista sufrió un golpe en la cabeza producto de un atropello y murió horas más tarde de un traumatismo encefálico, sin haber tenido acceso a un escáner porque el equipo del Hospital estaba estropeado): C.S. Rol No 9145-2009, cons. $15^{\circ}$ (Tercera Sala: redacción del Ministro Sergio Muñoz).

${ }^{67}$ Para una lectura crítica de este lugar común, Stein, A., "Contra la 'prueba libre”, traducción de Jorge Larroucau Torres, en Revista de Derecho, Universidad Austral, Vol. 26, No 2, 2013 (1997), pp. 245 ss. 
lo que se refiere a la valoración de este testimonio, en tanto, allí opera a plenitud la soberanía judicial.

1.1. En cuanto a la admisibilidad del testimonio médico los tribunales apuestan por la imparcialidad del profesional, incluso si él o ella trabajan en el mismo servicio que fue demandado, sobre todo cuando ocupa un puesto de jefatura ${ }^{68}$. Tal vez esa presunción de imparcialidad responda a que los jueces necesitan el relato del experto para evaluar los protocolos y las metodologías con que van a medir el cumplimiento de los deberes de cuidado, así como el riesgo inherente al servicio, por ejemplo, para saber si un daño fue causado o no por complicaciones que "se presentan habitualmente en los 30 días del postoperatorio" 69 . Esta amplitud en el estándar de admisibilidad puede corregirse por el peligro de una "conjura del silencio" entre los médicos: así, por ejemplo, la Corte de Valparaíso decidió en una ocasión que lo dicho por un equipo médico (en cuanto a que no se dieron cuenta de que la aguja se había roto durante la intervención) "no resulta plausible [...] pues supone una praxis errónea que no puede ser protegida por el silencio, tanto individual como colectivo"70. La herramienta empleada fue la tacha a los testigos, ya sea por su falta de imparcialidad (si se trata de médicos que participaron en la cirugía del paciente) o por interés en el caso (en el entendido de que el Fisco podría repetir luego en contra de ellos, artículo 358 No 6, Código de Procedimiento Civil: “tener en el pleito interés directo o indirecto”). Por cierto, para la Corte Suprema estas tachas no son leyes reguladoras de la prueba, de modo que no se preocupa de controlar su empleo ${ }^{71}$. Otra instancia en que eventualmente podría darse este riesgo corporativo son los informes elaborados por el Servicio Médico Legal en su rol de asistencia a los tribunales (DFL N 196, 1960).

Una regla de admisibilidad tan amplia como esta también puede morigerarse mediante cánones de exclusión, los que exigen un debate sobre varios aspectos: (i) la posibilidad de legislar reglas específicas de exclusión como, por ejemplo, el que no se consideren en juicio las propuestas de cobertura médica para el caso de operaciones no exitosas, como si ellas implicasen un reconocimiento de responsabilidad, tal como en las Federal Rules of Evidence estadounidenses (Rule 409); (ii) las excepciones a la confidencialidad de la información médica; (iii) el riesgo de falsos positivos en la declaración del experto, que es algo que capturó muy bien en 1976, para el caso de un psiquiatra,

${ }^{68}$ Cuello con Servicio de Salud Antofagasta y otros (la paciente murió de un shock hipovolémico tras la hemorragia que le causó un problema obstétrico), C.A. Antofagasta, 15 junio 2010, Rol N ${ }^{\circ}$ 113-2010, MJCH_MJJ24308, cons. $3^{\circ}$ (redacción del Ministro Óscar Clavería).

${ }^{69}$ Jara con Hospital Regional de Concepción (una apendicitis realizada un año y medio antes dejó en la paciente restos de apéndice cecal, de modo que fue necesaria una nueva operación), C.A. Concepción, 9 agosto 2009, Rol No 1499-2008, MJCH_MJJ21005, cons. 9º (redacción del Ministro Juan Villa).

${ }^{70}$ López con Cooper y otro, C.A. Valparaíso, 11 octubre 2011, Rol No 1285-2011, MJCH_MJJ29694, cons. $5^{\circ}$ (redacción del Ministro Jaime Arancibia).

${ }^{71}$ Aravena y otros con Servicio de Salud Concepción, C.S., 9 noviembre 2011, Rol No 4811-2009, MJCH_ MJJ29976, cons. $3^{\circ}$ (Tercera Sala: redacción del Ministro Héctor Carreño). 
Tarasoff $v$. The Regents of the University of California $;^{72}$ y (iv) el margen de inmunidad del experto que declara en el juicio. En Inglaterra, por ejemplo, la regla de inmunidad es bastante robusta, tanto como para proteger a un médico que declaró que era altamente improbable que los dos hijos de una mujer hubiesen fallecido por la causa natural de síndrome de muerte infantil súbita, lo que incluso llevó a la cárcel a la madre, hasta que dos años después se demostró que el médico no había considerado entre las variables de cálculo todos los factores ambientales y genéticos ${ }^{73}$. La justicia inglesa solo ha roto esta inmunidad -por un "diagnóstico en juicio"- en casos groseros, como el de una médico que sostuvo que la víctima de un accidente de tráfico sufrió de estrés postraumático (EPT), para luego decir que en realidad lo que padecía era una depresión con síntomas de EPT y, finalmente, declarar que el daño era parte de una "reacción de ajuste" al accidente y que no alcanzaba a EPT, lo que hizo que el monto de la indemnización se redujese de manera considerable ${ }^{74}$. En Chile, en tanto, se cuenta el caso de un médico que informó a la policía de que una menor fallecida presentaba el "ano dilatado, lo que hace presumir una violación”, aviso que en definitiva no le acarreó responsabilidad porque a pesar de que el diagnóstico fue errado el médico tenía el deber de entregar esa información (Estatuto Administrativo, artículo 55 letra K, Ley $\left.\mathrm{N}^{\circ} 18.834\right)^{75}$.

1.2. En cuanto a la valoración del testimonio del experto, pareciera que la soberanía judicial libera de ceñirse a las reglas acerca de la prueba testimonial y la prueba pericial del Código de Procedimiento Civil, aunque esta liberación es más bien aparente porque ese Código de 1903 no fue, en esta parte, un orden incompatible con un modelo de libre valoración. En efecto, la Corte Suprema ha sostenido que "los jueces de la instancia tienen facultades soberanas y privativas para ponderar y valorar las declaraciones de los testigos de las partes, para preferir a unos por sobre otros, tomando en cuenta con este fin diversas circunstancias que atañen o al número de ellos o a sus condiciones de calidad, ciencia, fama, imparcialidad o veracidad, o, en fin, a las contradicciones que pudieran aflorar de sus dichos"76. Es así que el tribunal está autorizado para atribuirle peso al testimonio (por ejemplo, que los cuatro testigos "ejercen la profesión médica y

${ }^{72}$ Larroucau, J., "Por un estándar amplio de admisibilidad de pruebas en la justicia civil”, en Actas del Congreso Internacional de Derecho. En homenaje al Centenario de la Escuela de Derecho de la Universidad de Valparaíso, Tomo IV, EDEVAL, Valparaíso, 2012, pp. 198-204, 212-214.

73 Devaney, S., "Commentary. The Loneliness of the Expert Witness. General Medical Council v. Meadow [2006] E.W.C.A 1390”, en Medical Law Review, 15, 2007, pp. 116-118.

${ }^{74}$ Devaney, S., "Commentary. Balancing Duties to the Court and Client: The Removal of Immunity from Suit of Expert Witness. Jones v. Kaney [2011] UKSC 13”, en Medical Law Review, 20, 2012, pp. 450-452.

${ }^{75}$ Zúñiga y otro con Servicio de Salud Concepción (el médico estuvo encargado de levantar el acta de la muerte por asfixia de la menor), C.A. Concepción, 27 marzo 2009, Rol No 1421-2007, MJCH_MJJ20114 cons. $6^{\circ}$ (redacción del Ministro César Panés): "Erróneo o no, el diagnóstico en la parte relativa al ataque sexual a la menor fue sólo de carácter tentativo o eventual, pues se habló de una "presunción» de violación, es decir, sin que se haya efectuado una aseveración categórica, sino que más bien se aludió a una mera probabilidad".

${ }^{76}$ León con García y otros (la paciente sufrió una luxación rotatoria del atlas-axis tras una intervención quirúrgica), C.S., 04 diciembre 2008, Rol No 2554-2007, MJCH_MJJ19042, cons. 16º (Tercera Sala: redacción del Ministro Adalis Oyarzún). 
que, por tal razón, sus atestados se revelan como más convincentes”) 77 o restárselo ("el mérito del informe médico legal solo viene a corroborar o reafirmar aquello que era posible inferir de la restantes probanzas allegadas") ${ }^{78}$. En el caso de que un profesional entregue tarde su informe, cuando las partes ya han sido citadas a oír sentencia, el juez debe declararlo inadmisible por extemporáneo, salvo que se justifique dicho atraso; si el juez decidiera tenerlo por acompañado, entonces deberá valorarlo ${ }^{79}$.

Ahora bien, en la tarea de asignarle peso al testimonio lo habitual es que el juez escoja entre dos (o más) versiones contradictorias entre sí, que versan sobre temas que el juez no domina. Este problema -el de un juez "perito de los peritos"- no es exclusivo de la responsabilidad civil médica, sino que es uno de los dilemas que arrastra el moderno Derecho de prueba. Lo que me interesa destacar aquí es que el peso asignado a los testimonios ayuda a diferenciar entre los juicios de probabilidad, de modo que un juicio (posible y probable) será más pesado que otro: por ejemplo, tendrá más peso el que un recién nacido internado en el Hospital haya muerto intoxicado por el potasio en su alimentación que por otras causas ${ }^{80}$, y será ese juicio de hecho -posible, probable y con más peso probatorio- el que motivará la sentencia definitiva.

\subsection{Máximas de la experiencia}

Los jueces acuden al "sentido común” para justificar la prueba de los principales elementos de la responsabilidad, como la culpa, la causalidad y el daño, así como la cuantificación de los perjuicios. Es la experiencia la que enseña que ciertos hechos no pueden sino provenir de la negligencia del demandado: así, por ejemplo, la caída de un hombre de noventa y siete años desde la camilla en que lo trasladan ${ }^{81}$, en el caso de una operación innecesaria y realizada sin el consentimiento del paciente ${ }^{82}$, si se le notifica tardíamente a un donante de sangre de que es portador de $\mathrm{VIH}^{83}$, si el Instituto de

${ }^{77}$ Belmar con Servicio de Salud Talcahuano y otras, C.S., 24 enero 2006, Rol No 5826-2005, MJCH_ MJJ10696, cons. $6^{\circ}$ (Tercera Sala: redacción del Ministro Adalis Oyarzún).

${ }^{78}$ Vega con Castillo (una cirugía para frenar una incontinencia urinaria grado uno terminó con una perforación en la vejiga de la paciente), C.S., 30 marzo 2009, Rol No 6779-07, MJCH_MJJ19690, cons. $7^{\circ}$ (Primera Sala: redacción del Ministro Juan Araya; voto en contra del Ministro Sergio Muñoz).

${ }^{79}$ Castillo y otros con Fisco de Chile (una persona que cumplía condena en la cárcel de Colina II, en Santiago, enfermó de gastritis aguda y luego falleció tras ser operado en la Posta Central), C.A. Santiago, 14 abril 2005, Rol No 6974-2001, Gaceta Jurídica, No 298, p. 87, cons. $5^{\circ}$ (redacción y voto en contra del Ministro Cornelio Villarroel).

${ }^{80}$ Parada y otros con Servicio de Salud Concepción, C.S., 31 agosto 2006, Rol No $1342-2006$, cons. $11^{\circ}$ y $14^{\circ}$ (Tercera Sala: redacción del Ministro Ricardo Gálvez).

${ }^{81}$ Morales y otra con Servicio de Salud Bío-Bío, C.S., 6 noviembre 2012, Rol Nº 5417-2012 (Tercera Sala: redacción del Abogado Integrante Alfredo Prieto).

${ }^{82}$ Fuentes con Servicio de Salud Concepción (en lugar de extirparle un lipoma axilar derecho, como se acordó con la paciente, se le extrajó una tumoración grasa, que además era benigna), C.A. Concepción, 6 noviembre 2006, Rol No 757-2006, vLex: 30861721 (redacción del Ministro Eliseo Araya).

${ }^{83}$ Huenchur con Servicio de Salud Llanquibue, Chiloé y Palena, C.S., 14 septiembre 2011, Rol No $7326-$ 2009, MJCH_MJJ29245 (Tercera Sala: redacción del Ministro Pedro Pierry); Morales y Bazan con Servicio de 
Salud Pública no envía dentro del plazo legal la confirmación de los resultados de dicho examen ${ }^{84}$, o si notifica de que es portador a una persona que no padece VIH (que fue el escenario que consolidó en nuestra justicia la indemnización del daño moral en sede contractual $)^{85}$, cuando se opera la cadera sana del paciente $e^{86}$, se quema a un menor con un electrobistur ${ }^{87}$, se mantiene en el cuerpo del paciente una cánula por veintisiete meses más de lo necesario ${ }^{88}$, al recetar un medicamento equivocado ${ }^{89}$, o aplicar una inyección en el lugar erróneo ${ }^{90}$, cuando se pone término unilateral a la asistencia médica y farmacológica dos años después del accidente sin justificación ${ }^{91}$, no se toma una radiografía antes de una laparoscopia ${ }^{92}$, no se practica una cesárea a tiempo ${ }^{93}$, se da un diagnóstico tardío de tuberculosis (por confundir el cuadro clínico con uno de VIH) ${ }^{94}$, no se anticipa

Salud Libertador Bernardo O'Higgins, C.A. Rancagua, 7 julio 2008, Rol No 1136-2007, cons. $5^{\circ}$ (redacción del Ministro Miguel Vásquez).

${ }^{84}$ O. V. con MediMatic S.A.: C.S., 6 agosto 2013, LegalPublishing: CL/JUR/1745/2013, Rol N $7492-$ 2012, cons. $4^{\circ}$ (Primera Sala: redacción del Ministro Mauricio Silva).

${ }^{85}$ Ruiz con Laboratorio Biológico S. A.: C.S., 5 noviembre 2001, Revista de Derecho y Jurisprudencia, Tomo XCVIII, sec. $1^{\text {a }}$, p. 234; también en Gaceta Jurídica, N N 257, analizado en Jana, A. y Tapia, M., "Daño moral en la responsabilidad contractual. A propósito de un fallo de la Corte Suprema de 5 de noviembre de 2001”, en Cuadernos de Análisis Jurídicos, Universidad Diego Portales, I, 2004, pp. 171 ss.

${ }^{86}$ Beraud con Elgueta y otros (se estableció la responsabilidad criminal de los dos cirujanos, así como también de la anestesista, la pabellonera y la arsenalera del equipo médico, y se obligó solidariamente al Fisco a pagar los daños que sufrió el paciente porque la cirugía tuvo lugar en el Hospital Militar de Santiago), C.S., 20 junio 1996, Fallos del Mes, No 451, Rol No 33393-1995, cons. 20º (redacción del Abogado Integrante Jorge Rodríguez).

${ }^{87}$ Palominos con Servicio de Salud Libertador Bernardo O'Higgins, C.S., 23 marzo 2006, Rol No 5818-2005 (Tercera Sala: redacción del Ministro Milton Juica).

${ }^{88}$ Ortiz con Servicio de Salud Concepción, C.A. Concepción, 13 mayo 2010, Rol No 1409-2009, cons. $5^{\circ}$ (redacción de la Ministra Sara Herrera).

${ }^{89}$ NN con Servicio de Salud Llanquibue, Chiloé y Palena (la iluminación del pabellón en donde se encontraban los fármacos era escasa y los medicamentos no fueron bien identificados por el funcionario a cargo), C.A. Puerto Montt, 6 marzo 2006, Rol No 738-2005 (redacción del Ministro Hernán Crisosto).

${ }^{90}$ Cortés con Hospital Quilpué y otros (una inyección que debió hacerse por vía intramuscular se hizo en una arteria, a un niño de cinco años, quien quedó con una pierna más corta, cicatrices y una incapacidad permanente), C.S., 29 octubre 2008, Rol N 1620-2007, MJCH_MJJ1747 (Tercera Sala: redacción del Abogado Integrante Benito Mauriz).

${ }^{91}$ Carrasco con Asociación Chilena de Seguridad (un trabajador fue pensionado por invalidez por una demencia postec y síndrome parkinsoniano), C.S., 11 octubre 2006, Rol No 1107-2005, vLex: 332735998 (Tercera Sala: redacción del Ministro Milton Juica).

92 Ocaranza con Robinson (se realizó una laparoscopia para encontrar un dispositivo intrauterino que no estaba en el cuerpo de la paciente), C.S., 28 noviembre 2006, Rol N 320-2005, vLex: 251249646 (Primera Sala: redacción de la Ministra Margarita Herreros; voto en contra del Ministro Jorge Rodríguez, quien cuestionó que el daño moral pudiera indemnizarse en el marco de un contrato).

${ }^{93}$ Lincolao con Servicio de Salud Araucanía Sur (el hijo de la paciente falleció asfixiado), C.S., 30 julio 2012, Rol No 355-2010 (Tercera Sala: redacción del Ministro Héctor Carreño; voto en contra de la Ministra Sonia Araneda y del Ministro Sergio Muñoz).

${ }^{94}$ Ramírez con Servicio de Salud Metropolitano Oriente, C.A. Santiago, 28 diciembre 1999, Gaceta Jurídica, No 234, Rol No 3129-1996 (redacción del Ministro Domingo Kokisch). 
el posible desmayo de un donante de sangre ${ }^{95}$, se posterga la decisión de si requiere un bypass un paciente que ya tuvo dos infartos ${ }^{96}$, se niega como médico de turno la atención a un menor en un caso de urgencia ${ }^{97}$, no se diagnostica a tiempo un embarazo tubario ${ }^{98}$, entre tantos otros. Nótese que en estos casos las máximas de la experiencia no exoneran de rendir pruebas, sino que ayudan a comprender la información disponible.

Lo mismo ocurre con la prueba del daño, sobre todo porque suele tratarse de un daño moral, como ocurre ante un diagnóstico tardío de cáncer ${ }^{99}$ o la muerte de un hijo, escenario este último en que el daño sufrido "es fácilmente explicable por el estrecho vínculo que los unía"100. Pero esto no implica que el daño moral no deba ser probado. Por ello es que se destaca el voto de minoría de la Ministra Sonia Araneda -en Salas con Servicio de Salud Metropolitano Norte-, en cuanto rechaza la apuesta de que "el daño moral no requiere de prueba atendida su naturaleza", una expectativa que lamentablemente ha sido alimentada por la propia jurisprudencia chilena ${ }^{101}$. En su voto, la Ministra Sonia Araneda hizo presente que el demandante debe, al menos, "demostrar la existencia del afecto y de la unidad familiar” con la víctima ${ }^{102}$, por escueta que suela ser esta prueba ${ }^{103}$. Por último, también a la hora de cuantificar en dinero estos intereses, los que son inconmensurables por

95 Villar con Servicio de Salud Metropolitano Central, C.A. Santiago, 15 marzo 1988, Gaceta Jurídica, $\mathrm{N}^{\circ} 105$, cons. $1^{\circ}$ (redacción del Abogado Integrante Julio Chaná).

${ }^{96}$ Ballón con Servicio de Salud Iquique (el paciente falleció sin que la junta de médicos tomase alguna decisión sobre el bypass), C.S., 29 agosto 2012, Rol No 9440-2009, cons. $21^{\circ}$ (Tercera Sala: redacción del Abogado Integrante Arnaldo Gorziglia).

${ }^{97}$ Aravena con Abubadba (un menor murió sin ser atendido de urgencia por el médico de turno), C.S., 28 enero 1999, Revista de Derecho y Jurisprudencia, Tomo XCVI, sec. 4a , cons. $2^{\circ}$ (redacción del Abogado Integrante Vivian Bullemore).

98 Thenoux con Servicio de Salud Iquique (el fallo de primera instancia resolvió que "la actora ha visto mermadas sus expectativas de realizarse como madre"), C.S., 31 enero 2014, Rol N 5070-2013, cons. $3^{\circ}$ (Tercera Sala: redacción del Ministro Sergio Muñoz).

99 González con Servicio de Salud Concepción, C.A. Concepción, 22 abril 2009, Rol No 2332-2007, MJCH_MJJ19971, cons. 10 (redacción de la Ministra Rosa Mackay): "Es un hecho público y que emana del sentido común, que las enfermedades malignas deben ser diagnosticadas precozmente, de manera de iniciar lo antes posible el tratamiento adecuado para evitar la evolución de la enfermedad".

${ }^{100}$ Retamales y otros con Servicio de Salud Metropolitano Norte e Ilustre Municipalidad de Quilicura, C.S., 23 diciembre 2011, Rol No 6669-2009, cons. $8^{\circ}$ (Tercera Sala: redacción del Ministro Pedro Pierry).

101 Por ejemplo, Celedón con Hospital Clínico Universidad Católica de Chile (el cadáver de la hija fue entregado a personas que no eran sus familiares e inhumado por estas), C.A. Santiago, 23 marzo 2001, Revista de Derecho y Jurisprudencia, Tomo XCVIII, sec. $2^{\mathrm{a}}$, p. 24 , cons. $2^{\circ}$ (redacción del Abogado Integrante Domingo Hernández): "El daño moral experimentado por los familiares más próximos de la víctima no requiere demostración”.

102 C.A. Santiago, 26 septiembre 2000, Gaceta Jurídica, Nº 243 (redacción del Abogado Integrante Roberto Jacob).

103 Un ejemplo de esta parquedad en la prueba del daño moral lo ofrece Gallardo y otros con Servicio de Salud Concepción (una mujer de cuarenta y un años, madre de cuatro hijos, murió por el retardo en ser intervenida), C.A. Concepción, 20 agosto 2009, Rol N $1088-2008$, LegalPublishing: CL/JUR/8373/2009, cons. $21^{\circ}$ (redacción del Abogado Integrante Patricio Mella). 
definición, como la muerte de un familiar ${ }^{104}$, los jueces utilizan el "sentido común”. Ello se nota especialmente en el daño biológico, cuando se invoca la experiencia para justificar la existencia del daño y el monto que se pagará con fines compensatorios: por ejemplo, a un menor por un daño cerebral ${ }^{105}$, a un hombre por la pérdida del pene ${ }^{106}$, en un caso de (in)determinación del sexo ${ }^{107}$, o en el daño estético ${ }^{108}$. Pero, recuérdese una vez más, estas máximas de la experiencia ayudan a procesar la información, sin que eximan a las partes de la carga de probar los hechos, ni de hacerlo por sobre un cierto umbral.

\section{CaRgas y ESTÁNDARES}

En 1992, en Saccan con Ortega, la Corte de San Miguel decidió que no había responsabilidad del odontólogo al no haberse probado "con una probabilidad lindante con la

${ }^{104}$ Rodríguez y otros con Servicio de Salud Concepción (la paciente murió por una falla multiorgánica después de un accidente de tránsito en que ella iba como copiloto), C.A. Concepción, 15 noviembre 2010, Rol No 378-2010, MJCH_MJJ25596, cons. $7^{\circ}$ (redacción del Ministro Diego Simpértigue): “En el caso de los hermanos, no cabe dudas que la relación es distinta a aquella que existe con los padres de la víctima y los hijos de la misma, por lo que es necesario probar no solo la cercanía, grados de afecto, el tipo de relación que tenían con cada uno de ellos, en definitiva, de qué manera se han visto afectados en cuanto a sus sentimientos, afectos, relaciones de cariño y aprecio, lo que no ha ocurrido ya que la prueba citada por el recurrente es de carácter genérico”.

105 Torres y otros con Servicio de Salud Talcabuano (el menor sufrió una encefalopatía cerebral hipóxica severa), C.A. Concepción, 18 diciembre 2003, Rol No 1703-2003, vLex: 30938570, cons. 16º (redacción de la Ministra Silvia Oneto): “A modo de ejemplo [este daño significa para sus padres que] nunca podrán escuchar de su hijo las palabras papá, mamá, los quiero; nunca podrán interactuar con él afectivamente, jamás una caricia o un gesto de cariño; nunca desarrollar las actividades que normalmente se producen al interior de una familia. Su demostración no requiere más que un simple razonamiento lógico a partir de lo que para la naturaleza humana constituye lo normal, ordinario o corriente"; también en Revista de Derecho y Jurisprudencia, Tomo CII, sec. 5a, pp. 163-180.

106 Aillapán con López y Servicio de Salud Llanquibue, Chiloé y Palena (el medico decidió operar a un paciente con fibrosis que era diabético, sin verificar este dato antes de operar, sin que el médico fuese especialista y a pesar de que era viable un tratamiento a base de medicamentos), C.A. Puerto Montt, 22 febrero 2005 , Rol N ${ }^{\circ}$ 116620-2003, Revista de Derecho y Jurisprudencia, Tomo CIV, sec. $5^{\text {a }}$, cons. $19^{\circ}$ (redacción de la Ministra Sylvia Aguayo): "Para un hombre de 54 años de edad [...] evidentemente ocasiona, amén de una incapacidad física, una molestia psíquica, una aflicción, un dolor, una pena enorme al verse imposibilitado en la demostración física de su afecto y de aquellos actos inherentes a las relaciones maritales".

${ }^{107}$ Núñez con Servicio de Salud del Maule (a una menor que nació en 1993 se le extirpación los testículos feminizantes por riesgo de que padeciera cáncer, pero una década después de esa operación sus padres confirmaron que su hijo es un varón), C.A. Talca, 28 julio 2010, Rol N 85-2009, MJCH_MJJ24441, cons. $11^{\circ}$ (redacción del Abogado Integrante Rodrigo Barcia): "El grave daño que se le ha causado al menor en su derecho a la identidad y dado que en el futuro deberá someterse a costosos tratamientos quirúrgicos y a sesiones psicológicas, y que el daño causado afecta un «interés extrapatrimonial» tan relevante para el ser humano como es la sexualidad".

108 Wagemann con Vidal, C.S., 28 enero 2011, Rol No 5849-09, cons. $31^{\circ}$ (Primera Sala: redacción del Ministro Sergio Muñoz): "La afectación anímica o psíquica ocasionada a la demandante, traducida en la aflicción, angustia, preocupación y molestias que ha padecido [además de] la edad de la actora -26 años a la época del incumplimiento contractual-". 
certeza que el resultado lesivo ha sido producido por la violación del deber de cuidado profesional" ${ }^{109}$. En los hechos, el demandado le había inyectado al paciente una solución que hizo que disminuyera la visión de su ojo derecho debido al medicamento contra la depresión, prescrito por su psiquiatra, que tomaba el paciente y que era ignorado por el odontólogo. Lo mismo que en Miranda, citado en las primeras páginas de este artículo, Saccan -uno de los pocos fallos que utilizan la expresión culpa profesional- se planteó como un juicio referente a la responsabilidad civil y penal del demandado, lo que a mi juicio explica el riguroso estándar de prueba aplicado por la Corte de San Miguel ("probabilidad lindante con la certeza"). Veinte años después de Saccan, a raíz de una paciente que ingresó a pabellón por un embarazo gemelar de treinta y ocho semanas, y en cuyo cuerpo se dejó olvidada una compresa de 830 gramos, la Corte Suprema decidiría que "las normas sobre carga de la prueba son siempre iguales cualquiera sea la fuente de responsabilidad y solo se diferencian en atención al contenido de la obligación o se modifican por la existencia de presunciones establecidas por el legislador" ${ }^{110}$. En este segundo juicio la decisión ya no aludía al estándar de prueba -un umbral que divide entre los hechos probados y los no probados-, sino que a la carga probatoria -una regla que dirime quién debe abastecer de información al juez-.

Cargas y estándares de prueba son dos figuras diferentes, con funciones y fines propios, aunque nuestra jurisprudencia no siempre haya marcado las distinciones como corresponde. Así, por ejemplo, la Corte de Concepción ha resuelto que, mientras la carga probatoria es del actor (porque "lo normal es que el Estado y los servicios públicos funcionen correctamente”), el estándar de prueba es la convicción del juez (“[la evidencia] no permite a estos sentenciadores formarse convicción en el sentido que el daño se haya debido a una deficiencia o mal funcionamiento del servicio") ${ }^{111}$. Un fallo como el recién citado de la Corte de Concepción ofrece un buen punto de partida para reflexionar sobre estas dos figuras del Derecho de prueba, y notar un par de cosas importantes: (i) por un lado, que la carga de la prueba no depende necesariamente del modo en que los sucesos ocurren, sino de quién es el que dispone de la información sobre esos hechos, de modo que perfectamente la carga probatoria podría ser compartida por los dos litigantes en algunos casos; y, (ii) por otro lado, reflexionar acerca de si la convicción del juez puede

109 C.A. San Miguel, 15 abril 1992, Gaceta Jurídica, No 143 , cons. $21^{\circ}$ (redacción del Ministro Rafael Huerta); también en Revista de Derecho y Jurisprudencia, Tomo LXXXIX, sec. $2^{\text {a }}$, citado en Larroucau, J., Culpa y dolo en la responsabilidad extracontractual. Análisis jurisprudencial, LegalPublishing, Santiago de Chile, 2007, 4a reimpresión, 2010, p. 199.

${ }^{110}$ González con Servicio de Salud Valparaíso San Antonio y Martínez, C.S., 12 diciembre 2012, Rol No 3591 2010, cons. $9^{\circ}$ (Tercera Sala: redacción del Ministro Sergio Muñoz). La misma idea ha insinuado Domínguez, C., "El problema de la culpa presunta contractual y las obligaciones de medio y resultado: sus implicancias para la responsabilidad médica”, en Cuadernos de Análisis Jurídico, Íñigo de la Maza compilador, Universidad Diego Portales, VI, 2010, p. 44.

${ }^{111}$ Castro con Servicio de Salud Bío-Bío (a un recién nacido tuvo que amputársele su mano izquierda en un Hospital de Los Ángeles, tras sufrir un vasoespasmo arterial severo debido a una punción en la arteria humeral del brazo), C.A. Concepción, 12 mayo 2009, Rol No 72-2008, cons. $8^{\circ}, 12^{\circ}$ y $13^{\circ}$ (redacción del Abogado Integrante Hugo Tapia): "[El daño proviene de] una complicación y riesgo propios de su estado clínico [del recién nacido], imprevisible [para el personal del Hospital]”. 
ser un estándar de prueba, porque es sabido que si ella es algo subjetivo entonces se vuelve improbable una revisión del juicio de hecho por parte de las Cortes (un blindaje que la soberanía judicial promueve en Chile).

\section{Carga de la prueba}

La carga de la prueba establece qué parte debe informar al juez sobre los hechos discutidos. Que el juez se entere por sí mismo no es algo deseable, no porque pueda ser parcial en la recolección de las pruebas, sino porque sería demasiado costoso para la administración de justicia encomendarle una tarea así. Lo razonable, entonces, es que se consideren las facilidades de acceso a la información cuando se impone la carga de la prueba, en lugar de otros factores, como la posición que ocupan los sujetos en el litigio. Estas cargas hacen más probable que el juez conozca lo que realmente ocurrió en cada ocasión. De allí que una regla como la del año 2004 (artículo 38 inciso $2^{\circ}$, Ley $\mathrm{N}^{\circ}$ 19.966) sea deficiente si se la entiende como una disposición que inhibe a los servicios públicos de salud de aportar información al juicio ("El particular deberá acreditar que el daño se produjo por la acción u omisión del órgano, mediando dicha falta de servicio"). La lectura que debe prevalecer es la que hiciera la Corte Suprema, en el citado caso González con Servicio de Salud Valparaíso San Antonio y Martínez, cuando vincula a la carga de la prueba con el "contenido de la obligación", aceptando que sea corregida por medio de presunciones si, por ejemplo, el contenido de la obligación aleja a la carga de aquel que controla las evidencias ${ }^{112}$. Así, en un caso como Godoy y otros con Servicio de Salud Valdivia, en que el encargado de limpiar las ropas del Hospital se pinchó un dedo con una jeringa oculta en el bolsillo de un delantal, un día en que hubo dos punciones, una a un paciente con leucemia, otra a un paciente con VIH, eera el trabajador ("el particular") quien debía aportar toda la información sobre las cuestiones de hecho discutidas? La Corte de Valdivia resolvió -correctamente a mi juicio- que no, ya que era el Hospital quien debía informar sobre cómo había operado el desecho de los materiales quirúrgicos ese día ${ }^{113}$.

Siguiendo el punto de vista de la Corte Suprema en González, entonces, como la obligación que se contrae en la medicina normalmente es una de medio, la carga de la prueba debería ser compartida por ambas partes. De ese modo, mientras que la víctima intentará acreditar el incumplimiento de la obligación, la demandada tratará de probar su cumplimiento (que su diagnóstico extinguió su obligación, por ejemplo) ${ }^{114}$. Ello es

112 Aquí radica el debate sobre la distribución (judicial o legal) de la carga de la prueba por motivos de disponibilidad. Cabe notar que -al amparo de un orden normativo semejante al chileno- la Corte Suprema colombiana autorizó, el año 2001, a modificar la carga de la prueba según la disponibilidad probatoria, Cortés, E., "Culpa y responsabilidad médica en Colombia y Chile", en Roma e America. Rivista di Diritto dell'Integrazione e Unificazione del Diritto en Europa e in America Latina, Mucchi Editore, 21, 2006, p. 195.

113 C.A. Valdivia, 09 mayo 2005, Rol N 937-2004, LegalPublishing: CL/JUR/2120/2004, cons. $18^{\circ}$ (redacción del Ministro Darío Carretta).

${ }^{114}$ NN con Sanatorio Alemán S.A., C.A. Concepción, 19 julio 2012, Rol No 456-2012, vLex: 395485462 , cons. $5^{\circ}$ (redacción del Ministro Carlos Aldana). 
así debido a que en las obligaciones de medio la pregunta por el cumplimiento (o incumplimiento) del deudor "inevitablemente exige preguntarse" por la diligencia (o culpa) de ese deudor ${ }^{115}$. Considero que esta regla práctica -imponer una carga de la prueba compartida- sirve mejor a los juicios de responsabilidad médica que una distinción conceptual de carga de la prueba “por etapas”, en donde la víctima prueba la obligación (primera etapa) para que luego el demandado pruebe su cumplimiento (= diligencia, extinción de la obligación, pago) (segunda etapa) ${ }^{116}$. Los recelos ante una carga de la prueba compartida por los litigantes, y el hecho mismo de que la discusión académica se haya empozado en esta parte, podrían explicarse por una imagen distorsionada de la función que cumple la carga de la prueba. Dicho de otro modo, la discusión sobre la carga de la prueba ha sido intensa porque no ha sido una discusión relativa a la carga de la prueba, sino que sobre el estándar de prueba. La tendencia a leer la carga como un estándar es un error que en la literatura de prueba se conoce como la "aproximación de la 'máquina expendedora”" (slot-machine) ${ }^{117}$, según esta, cuando subsisten dudas acerca de los hechos del caso -ya sea porque los datos son ambiguos, escasos, contradictorios, de mala calidad, o por el motivo que fuere-, el juez debe tomar la carga de la prueba cual ficha e insertarla en el litigio para obtener un resultado: este resultado será siempre, por cierto, fallar en contra de quien tenía la carga probatoria; de allí que la estrategia colapse si la carga es compartida. La arbitrariedad que alberga esta forma de comprender el juicio de hecho ha sido aludida en otro lugar ${ }^{118}$, por lo que ahora solo resta insistir en que la carga probatoria no pretende zanjar los hechos probados, sino que hacer probable que el juez disponga de la información relevante para decidir el caso.

Ahora bien, si la obligación que contrajo el médico es de resultado, entonces sí existen razones para que la carga de la prueba solo recaiga en él: (i) porque se trata de prestaciones de un valor acotado (como las cirugías plásticas), en donde hay una clara desproporción entre el riesgo que asume el paciente y los daños que puede padecer, (ii) porque "el deudor debe controlar de tal modo el riesgo, que la experiencia enseña prima facie que el error se debe a la culpa del deudor" 119 y, (iii) por la regla probatoria de los hechos negativos, que autoriza decisiones como ésta: "El paciente al afirmar haber sido víctima de una 'mala praxis', de una atención 'defectuosa' o una que califica como 'no atención', está aseverando un hecho negativo, correspondiendo inferir de esto que es el médico o facultativo el que deberá probar que sí empleo los medios idóneos a su alcance,

115 Barros (n. 5) p. 659.

116 Esta interpretación "conceptual" de la carga de la prueba atiende especialmente a dos reglas del Código Civil: "La prueba de la diligencia o cuidado incumbe al que ha debido emplearlo", artículo 1547 inciso $3^{\circ}$; "Incumbe probar las obligaciones o su extinción al que alega aquellas o estas", artículo 1698; Pizarro, C., "La culpa como elemento constitutivo del incumplimiento en las obligaciones de medio o de diligencia”, en Revista de Derecho, Pontificia Universidad Católica de Valparaíso, XXXI, 2008, pp. $260-264$.

117 Stein, A., "The Refoundation of Evidence Law", en Canadian Journal of Law E Jurisprudence, Vol. 9, 1996, pp. 317-318.

${ }^{118}$ Larroucau, J., "Hacia un estándar de prueba civil”, en Revista Chilena de Derecho, Pontificia Universidad Católica de Chile, Vol. 39, No 3, 2012, pp. 794-795.

119 Barros (n. 5), pp. 661-662, 679-680. 
para cumplir el cometido encargado" ${ }^{120}$. Es por ello que la prueba de una obligación de resultado opera de forma análoga a las presunciones de culpa en sede extracontractual. Si la única eximente -regla de salida- del demandado va a ser el caso fortuito, o bien se le aceptará también la prueba de su diligencia, eso es algo que va a depender de si esta obligación de resultado se asemeja o no a una garantía, algo que finalmente deriva del modo en que se interpreta la regla contractual en las prestaciones médicas.

\section{Estándar de prueba}

Como el juez no puede excusarse de fallar el caso incluso cuando los hechos son inciertos (artículo 10 inciso 2, Código Orgánico de Tribunales), es preciso disponer de una forma que le permita sacar adelante esa decisión. En el Derecho de prueba esta es la función del estándar probatorio, que le permite al juez tomar una decisión racional y controlable acerca de los hechos probados. Esto en la justicia patrimonial tiende a expresarse en la regla de probabilidad prevaleciente $(\mathrm{P}>0,5)$, la que denota el grado de confirmación de los hechos respecto de las pruebas disponibles. Y es aquí donde la justicia chilena exhibe, tal vez, sus mayores falencias: (i) por una parte, ella acude sin ningún reparo a la convicción del juez para consignar en la sentencia los hechos probados y, (ii) por otro lado, no distingue entre el estándar de prueba civil y el estándar penal cuando se fijan esos hechos. Este es un panorama que debe ser corregido, (i) ya que la convicción judicial -entendida como algo subjetivo- es un falso estándar, porque no informa de ninguna de las razones tomadas en cuenta para decidir que las evidencias confirmaban o no los hechos, de modo que acudir a ella contradice el sentido que tiene motivar el fallo y hace estéril cualquier recurso procesal que prometa una revisión de los hechos; en segundo término, porque las exigencias para establecer los hechos en que se funda una decisión sobre la responsabilidad civil no pueden ser medidas con la vara del Derecho penal. Estos son los dos temas con que se cierra el artículo. La buena noticia pareciera venir dada por el res ipsa loquitur, que es empleado en varias de las decisiones judiciales, y que podría sentar las bases normativas que sirvan para enmendar prácticas como las descritas.

\subsection{Convicción (soberanía) judicial}

Cuando se leen los fallos sobre responsabilidad médica en Chile no queda ninguna duda de que el fin de la prueba es convencer al juez de que los hechos (no) ocurrieron ${ }^{121}$. De allí que un juez descarte esa responsabilidad si decide que "la prueba pericial, documental,

${ }^{120}$ Pedrero y otro con Pinto, C.A. Santiago, 22 septiembre 2006, Rol N ${ }^{\circ}$ 5515-2001, cons. $4^{\circ}$ (Cuarta Sala: redacción del Abogado Integrante Nelson Pozo).

${ }^{121}$ En el mismo sentido se ha inclinado una parte de la literatura civil: así, por ejemplo, Domínguez, R., "Comentarios de jurisprudencia. Necesidad de prueba del daño moral. No basta acreditar un vínculo de filiación”, en Revista de Derecho, Universidad de Concepción, No 225-226, 2009, p. 295: "Es la prueba la que garantiza que el juzgado [sic] se haya convencido acerca de la verdad de las proposiciones de las partes". 
testifical y confesional rendidas en este juicio no permiten formar plena convicción" ${ }^{22}$, o la acoja cuando "arriba al convencimiento que la aplicación de la vacuna fue la causante de la reacción negativa que se produjo en el organismo del menor consistente en una encefalitis infecciosa" ${ }^{" 123}$, en un ejercicio que alcanza tanto a las obligaciones de medio ("permitieron la convicción del sentenciador") ${ }^{124}$ como de resultado ("la especialidad del profesional permite concluir con mayor grado de convicción su incumplimiento") ${ }^{125}$. En este escenario, ¿cómo podría un litigante refutar o compartir el grado de confirmación de los hechos, si de lo único que se le informa es de la convicción del juez? Por ejemplo, si se rechaza la demanda porque no existió "certeza" de que la paciente expulsara por vía anal una compresa quirúrgica tras una operación ${ }^{126}$, o porque para los Ministros de una Corte de Apelaciones "no hay prueba alguna que les forme convencimiento" de que la detección tardía de una fractura de cotilo provino de un descuido en el Hospital ${ }^{127}$, ¿puede cuestionarse el juicio de hecho?

La Corte Suprema ha atemperado la soberanía judicial diciendo que "la actividad jurisdiccional considera un componente básico de prudencia en la decisión" ${ }^{128}$, pero al decir esto no parece notar que un estándar de prueba basado en la prudencia solo es viable si el juez respalda sus decisiones en criterios objetivos, como podrían ser la gravedad y las consecuencias que acarrea para una persona el que un hecho sea tenido por cierto en un litigio ${ }^{129}$. Si bien para la Corte Suprema las leyes reguladoras de la prueba y la motivación de los fallos deberían cumplir este rol ("la fundamentación de las sentencias importa para las partes y el tribunal superior, quedar en posición de poder conocer, rebatir, impugnar y revisar, en su caso, las razones que formaron la convicción del juzgador,

122 Álamos y otros con Corporación Iglesia Adventista del Séptimo Día (la paciente falleció debido a un infarto al miocardio), C.A. Concepción, 12 abril 2013, Rol N 1433-2012, cons. $8^{\circ}$ (redacción del Ministro Claudio Gutiérrez).

123 Daza con Servicio de Salud Concepción, C.A. Concepción, 3 noviembre 2005, Rol N 1610-2002, cons. $7^{\circ}$ (redacción del Abogado Integrante Jorge Caro).

${ }^{124}$ Burkbardt y otro con Servicio de Salud Bío-Bío (el paciente ingresó de urgencia al Hospital y no se le practicó ningún examen, por lo que solo se le detectó una fractura en el cráneo en una segunda atención, efectuada siete horas después de su caída, falleciendo finalmente por una neumonía/accidente vascular isquémico): C.S., 16 enero 2013, Rol No 9347-2012, cons. $4^{\circ}$ (Tercera Sala: redacción del Abogado Integrante Guillermo Piedrabuena).

125 Wagemann con Vidal, C.S., 28 enero 2011, Rol N 5849-09, cons. $10^{\circ}$ (Primera Sala: redacción del Ministro Sergio Muñoz).

126 Vargas con Servicio de Salud Llanquibue Chiloé y Palena, C.A. Puerto Montt, 3 septiembre 2007, Rol No 935-2006, cons. 14º (redacción del Ministro Hernán Crisosto).

${ }^{127}$ Leva con Servicio de Salud Coquimbo, C.A. La Serena, 24 septiembre 2008, Rol No 240-2008, Gaceta Jurídica $\mathrm{N}^{\circ} 347$, cons. $4^{\circ}$ (redacción del Abogado Integrante Manuel Cortés).

${ }^{128}$ Por todos, Sepúlveda con Servicio de Salud Maule (el hijo nació muerto tras romperse la membrana producto de una infección ovarial que sufrió la madre), C.S., 9 enero 2013, Rol N N $^{\circ} 2004-2010$, cons. $4^{\circ}$ (Tercera Sala: redacción del Ministro Pedro Pierry).

129 Ho, H. L., A Philosophy of Evidence Law. Justice in the Search for Truth, Oxford Monographs on Criminal Law, Oxford University Press, 2008, pp. 213-229. 
comprometiendo así aspectos de orden público que no es posible soslayar") ${ }^{130}$, en la práctica no se observa cómo estas herramientas hacen posible "conocer, rebatir, impugnar y revisar" el juicio de hecho. Si bien esta es una cuestión que precisa de un estudio aparte, es necesario dejar constancia de un exceso de confianza en el vocabulario usado; en la fuerza de palabras como "certeza" y de frases como "formar plena convicción". De allí que, por ejemplo, la Corte de Concepción ratificase un fallo absolutorio porque "en el informe del Servicio Médico Legal, aludido en el $6^{\circ}$, las afirmaciones que contiene no son categóricas, empleándose expresiones dubitativas como 'creemos', o 'aparentemente”"131, o la Corte Suprema se negase a revisar la valoración de un testimonio, porque "está claro que esa disposición [artículo $384 \mathrm{~N}^{\circ} 2 \mathrm{CPC}$ ] no es una ley reguladora de la prueba, ya que la demostración del hecho, al emplear la ley la palabra 'podrá', queda entregada a la apreciación soberana de los jueces de la instancia" ${ }^{132}$. Esto, más que prudencia, lo que respalda es la discrecionalidad judicial.

Para "poder conocer, rebatir, impugnar y revisar, en su caso, las razones que formaron la convicción del juzgador" (Montes con Toloza), este debe justificar sus decisiones probatorias al motivar la sentencia. De lo contrario, los verbos anteriores se diluyen y vale lo dicho en 1989 por Daniel Peñailillo para la prueba que se valora en conciencia, en cuanto a que incluso un modelo que apelase a la conciencia debería entenderse "como una toma de conciencia razonada [porque] como no es posible jerarquizar las conciencias en la misma forma en que están jerarquizados los tribunales, el sistema [de persuasión moral o íntimo convencimiento] estorba la justificación de los recursos procesales. La revisión de los hechos no sería posible, pues el tribunal superior no podría arrogarse mayor o mejor conciencia que el inferior"133. La convicción judicial, tal como parece entenderla la justicia civil chilena, como algo que "le sucede" al juez o a la jueza, ha dejado inerte el sistema de recursos procesales en cuanto a la revisión de los hechos.

Lo segundo que se aprende al leer la jurisprudencia es que al demandar la responsabilidad civil en un juicio penal se corre el riesgo de que el rechazo de la acción penal arrastre siempre a la acción civil. Así, de entre varios otros ejemplos, Donoso con Núñez ${ }^{134}$, Garrido y otro con Sánchez y Servicio Nacional de Salud O'Higgins ${ }^{135}$, Monje con Redondo y

${ }^{130}$ Montes con Toloza, C.S., 4 octubre 2007, Rol N 3299-2007, cons. $7^{\circ}$ (Segunda Sala: redacción del Ministro Raúl Ballesteros).

${ }^{131}$ Rifo y otro con Silva y otro (el recién nacido sufrió un daño neuronal debido a que tenía el cordón umbilical alrededor de su cuello, sin que se decidiera practicar una cesárea), C.A. Concepción, 5 agosto 2008, Rol No 951-2007, MJCH_MJJ17905, cons. 9.

132 Pincheira con Servicio de Salud Llanquibue, Chiloé y Palena (tras una cirugía se dejó en el cuerpo del paciente una compresa), C.S., 25 mayo 2006, Rol No 6350-05, cons. $13^{\circ}$ (Tercera Sala: redacción del Ministro Milton Juica).

133 Peñailillo, D., La prueba en materia sustantiva civil. Parte general, Editorial Jurídica de Chile, Santiago, 1989, pp. 19 (n. 27), 25, 89-93.

134 C.S., 30 noviembre 2009, Rol N 6384-2008, cons. 22º (Segunda Sala: redacción del Ministro Hugo Dolmestch).

135 C.S., 4 junio 2008, Rol No 434-2008 (Segunda Sala: redacción del Ministro Jaime Rodríguez). 
otros (con el voto en contra de la Ministra Alicia Araneda) ${ }^{136}$, Raiman con Márquez y Vásquez ${ }^{137}$, y los casos de Miranda y Saccan ya citados. Ni los jueces de instancia, ni tampoco la Segunda Sala de la Corte Suprema se han esforzado por aclarar si esto ocurre debido a diferencias en cuanto a los requisitos de la responsabilidad o por razones de prueba. A modo de ejemplo, en Fuenzalida con Araneda y otros, la Corte Suprema decidió que por una pinza olvidada en el abdomen de una mujer no debía responder el Hospital, usando un buen razonamiento en cuanto a la prueba rendida: "hay evidencia científica de que un instrumento como ese puede permanecer largo tiempo alojado en el cuerpo de una persona, sin perjudicar su salud, incluso, sin causarle molestias apreciables, es perfectamente posible que se haya encontrado allí desde que se la operó varios años atrás, cosa que resulta tanto más verosímil si se tiene en cuenta que la mencionada pinza no corresponde al tipo ni lleva la marca de las que se emplean en el Hospital"138, pero sin hacerse cargo, en ningún momento, de cuán "verosímil” debía ser dicha confirmación debido a la responsabilidad en juego.

El problema aquí es que los jueces terminen aplicando un estándar penal a las pretensiones civiles. Ello se grafica en un caso como Olivares con Zuleta, en donde una menor de dos años fue ingresada a una Clínica para que se le extrajeran las amígdalas, siendo encontrada algunas horas más tarde por su madre con una quemadura en la espalda ${ }^{139}$. En ese caso la sentencia de primera instancia descartó la responsabilidad civil porque desechó la responsabilidad penal de la funcionaria acusada, a pesar de que el estándar civil -como lo marca la probabilidad prevaleciente- es menos exigente que el estándar de prueba penal ("más allá de toda duda razonable"). Si bien la Corte de Iquique corrigió esta situación mediante la regla de entrada de la culpa organizacional ${ }^{140}$, el problema sigue vigente: al equiparar los estándares de prueba los jueces trasladan la distribución de los riesgos de error de la ley penal ("más vale liberar a un culpable que condenar a un inocente”) fuera de su marco de justificación, lo que blinda más allá de la cuenta al demandado de responder civilmente ${ }^{141}$.

136 C.A. Coyhaique, 5 marzo 2008, Rol No 32-2007 (redacción del Ministro Sergio Vásquez).

137 C.S., 21 octubre 2008, Rol N 15686-2006 (Segunda Sala: redacción del Ministro Juan Muñoz).

138 C.S., 16 marzo 1998, Rol No 4381-1997, Gaceta Jurídica, No 213, p. 112, cons $7^{\circ}$ (Segunda Sala: redacción del Ministro Enrique Cury).

139 Juzgado de Letras de Iquique, 29 septiembre 2001, Rol Nº 15939-6, LegalPublishing No 26334 , cons. $10^{\circ}$ (redacción del Juez Pablo Muñoz).

${ }^{140}$ C.A. Iquique, 9 enero 2002, Rol No 239727, LegalPublishing No 26334, cons. $3^{\circ}$ (redacción de la Ministra Eliana Ayala): "De esta manera es posible sostener que el acto que causó daño a la paciente no constituye responsabilidad penal, por no existir dolo o culpa penal, pero sí, una responsabilidad civil, que no debe hacerse a costa del equipo médico sino de la clínica respectiva, por no realizar actividades o gestiones que le obligan a una mantención continua y periódica de equipo utilizado en la operación de la víctima”. Esta decisión no fue modificada por la Corte Suprema (2 abril 2003, Gaceta Jurídica, No 274).

${ }^{141}$ Larroucau (n. 118), pp. 787-788. 


\subsection{Res ipsa loquitur}

Para acudir a esta categoría es necesario que se den ciertos requisitos ${ }^{142}$ : (i) que el daño sufrido normalmente no ocurra sin la culpa de una persona, (ii) que haya sido provocado por algo que estaba bajo el exclusivo control del demandado, (iii) sin la contribución de la víctima y (iv) sin que se disponga de más información acerca de los hechos. Esta figura ha sido explorada en Chile a raíz de la presunción de culpa por el hecho propio que cobija el artículo $2329^{143}$, y admite una lectura débil y una fuerte. Bajo un enfoque débil, como la culpa del demandado es solo una de las posibles explicaciones para el daño, ya que siempre queda abierta la posibilidad de la mala suerte, el res ipsa loquitur autoriza al juez para que decida si el caso corresponde a uno de injusticia o a uno de infortunio, aunque su inferencia no goce de un respaldo epistémico irreprochable. Esto es, habilita al juez para asumir el riesgo de equivocarse en su decisión y radicar ese riesgo en la demandada cuando las condiciones antes señaladas cumplen el estándar de la probabilidad prevaleciente $(P>0,5)$. En consecuencia, si bien existe una "alteración del riesgo de la prueba" ${ }^{144}$, en un sentido profundo esta figura no se limita a reconstruir los hechos pasados de un modo correcto - promoviendo que la demandada rinda pruebas sobre los requisitos ii y iv-, sino que provee de una regla de decisión para distribuir los riegos de error en contextos de incertidumbre. En su versión débil, entonces, el res ipsa loquitur permite escribir un considerando como el que sigue: "[Los] hechos acreditados constituyen indicios suficientes que permiten presumir la existencia de la falta de servicio [pues] no existe ningún otro antecedente que explique la razón de la infección que le ocasionó al actor los padecimientos cuya indemnización demanda que no sea la presencia de tales elementos o cuerpos extraños en su organismo"145.

La interpretación fuerte, en cambio, apunta hacia el empleo de la probabilidad estadística en los juicios de imputación civil (requisitos i, ii y iii). En este enfoque, es suficiente con probar que la conducta del demandado pertenece a una categoría de conductas que provocan daños de manera habitual para que el juez civil declare la responsabilidad. Esto es, no se atiende a la acción u omisión del demandado en concreto, sino que al tipo de conducta en que se encuadra su comportamiento. De allí que la razón subyacente al res ipsa loquitur en su lectura fuerte sea, por ejemplo, la misma que en la regla del mercado compartido, de modo que si la responsabilidad médica es leída en términos menos estrechos que la de una demanda judicial de un paciente en contra de un médico, el res ipsa loquitur podría configurar -entre otras aplicaciones- una regla

142 Porat, A. y Stein, A., Tort Liability under Uncertainty, Oxford University Press, 2001, pp. 84-85.

${ }^{143}$ Larroucau, J., "Res ipsa loquitur: Quien habla es el juez, no la cosa”, en Estudios de Derecho Civil VI, Gonzalo Figueroa, Enrique Barros y Mauricio Tapia (coord.), LegalPublishing, Santiago de Chile, 2011, pp. 491-519.

${ }^{144}$ Barros (n. 5), p. 157.

145 Rosales con Servicio de Salud Metropolitano Oriente (las compresas que se olvidaron en el paciente después de la operación le causaron una infección que obligaría a extirparle el colon), C.S., 31 julio 2012, Rol N 9140-2009, cons. $3^{\circ}$ (Tercera Sala: redacción del Ministro Héctor Carreño). 
de entrada para los daños causados por medicamentos, cuando las víctimas no pueden probar qué farmacéutica fue la que los elaboró o vendió.

Como en su lectura débil el res ipsa loquitur apela a lo que normalmente ocurre: si es habitual o no dejar en un paciente una gasa, una aguja ${ }^{146}$, un bisturí ${ }^{147}$, el juicio de probabilidad que allí se confecciona descansa en un modelo pascaliano, no baconiano, porque se predica de sucesos y se asume como una frecuencia relativa ${ }^{148}$. Creo que lo habitual en los juicios de responsabilidad médica es pensar en términos baconianos -el diagnóstico es un claro ejemplo-, pero ello cambia en el res ipsa loquitur, cuyas probabilidades se determinan en términos pascalianos: el suceso más recurrente es la gravedad del daño ${ }^{149}$, de allí que el Tribunal Supremo español hablase de "daño desproporcionado" ${ }^{150}$, cuya intensidad y frecuencia es lo que autoriza al juez a inferir la responsabilidad ${ }^{151}$.

Ahora bien, aunque algunos casos son bastante claros ${ }^{152}$, como se trata de una potestad judicial es posible que el juez decida no inferir la responsabilidad: así ocurrió, por ejemplo, con una paciente que se sometió a una colonoscopia y quedó en un estado semivegetal ${ }^{153}$. Con todo, en la práctica judicial chilena el res ipsa loquitur se ha aplicado incluso si han pasado algunos años entre la intervención médica y el descubrimiento del objeto ${ }^{154}$, e incluso en juicios donde se discutía la responsabilidad penal del profesional ${ }^{155}$, aunque no siempre: por ejemplo, en Rebolledo con Sabat, la Corte Suprema descartó la demanda

146 Sepúlveda con Servicio de Salud Talcahuano (tras ser operado de cálculos biliares se dejó una aguja de sutura en el hígado del paciente), C.A. Concepción, 13 diciembre 2010, Rol N 413-2010 (redacción de la Abogada Integrante Ruth Gabriela Lanata).

147 Gómez con Servicio de Salud Talcabuano y Echeverría (se le hizo una cesárea a la paciente), C.A. Concepción, 22 octubre 2010, Rol N 704-2010, cons. $16^{\circ}$ (redacción del Ministro Jaime Solís).

148 Twining, W., "Debating Probabilities”, en The Liverpool Law Review, 2, 1980, pp. 53-54.

${ }^{149}$ Castro con Servicio de Salud Bío-Bio (un recién nacido prematuro sufrió un espasmo arterial y no fue monitoreado durante aproximadamente diez horas, lapso en que su estado se agravó hasta que finalmente falleció), C.S., 13 octubre 2011, Rol No 4751-2009, vLex: 333057422, cons. $20^{\circ}$ (Tercera Sala: redacción del Ministro Pedro Pierry).

${ }^{150}$ Luna, Á., "Oblit d'una gasa durant una intervenció quirúrgica”, en InDret, Barcelona, 2, 2003, pp. 5-8.

${ }^{151}$ Rochet con Oksenberg y Clínica Las Nieves S.A. (una cirugía de circuncisión que se hizo por motivos religiosos dejó heridas en el menor debido a una mala colocación de las costuras, lo que obligó a una operación reconstructora del pene), C.S., 25 marzo 2008, Rol No 4931-2006, vLex: 332688522 (Tercera Sala: redacción del Ministro Pedro Pierry).

152 Delgado con Hospital Dr. Sótero del Río (la dependiente trabajaba como auxiliar de alimentación y confundió una sonda esofágica que se instala en la nariz, con un catéter venoso que sale de la cara lateral del cuello), C.A. San Miguel, 17 octubre 2012, Rol N 609-2012, vLex: 405287470, cons. $10^{\circ}$ (redacción del Abogado Integrante Manuel Hazbún).

153 Burgos con Servicio de Salud Metropolitano Sur, C.A. San Miguel, 20 marzo 2008, Rol N 1788-2003, cons. $17^{\circ}$ (redacción de la Ministra Ana María Arratia).

${ }^{154}$ NN con Servicio de Salud Viña del Mar (la cesárea tuvo lugar el 2004 en un Hospital de San Felipe, encontrándose restos de una aguja en su abdomen el 2006, y un apósito en su vagina el 2007), C.A. Valparaíso, 20 octubre 2011, Rol N 1114-2011, vLex: 331922958, cons. 6º (redacción de la Ministra María Angélica Repetto).

155 Martínez con Zarbi (la compresa de gasa quedó en el cuerpo de la paciente tras una operación a las mamas), C.S., 3 junio 2009, Rol No 4158-08, MJCH_MJJ20084 (Segunda Sala: redacción del Ministro Carlos Künsemüller). 
porque "la intervención quirúrgica realizada no fue una operación sencilla [aunque] luego de la utilización de gran cantidad de pinzas quirúrgicas, debido a la premura en aras del bien superior que era evitar la muerte del paciente, quedó olvidada una de ellas al interior del cuerpo del ofendido"156. Para la Corte Suprema el médico de turno del Hospital:

“realizó su labor en buena forma, salvando la vida del ofendido quien presentaba heridas vitales y graves, por acción de armas blancas, además de un estado de ebriedad manifiesto. No siendo posible que en medio de una intervención quirúrgica complicada en la labor del médico, su trabajo también deba ser de supervigilancia de cada uno de los actos de las demás personas que intervengan en el proceso médico que se lleva a cabo" (cons. $8^{\circ}$ ).

Si bien este fallo coincide con la tendencia a rebajar el umbral de cuidado en las atenciones de urgencia (hasta la culpa grave) y donde, además, la causa del daño es el hecho de un tercero -la herida con "arma blanca"-, cabe notar otra vez la insensata influencia que ejerce la responsabilidad penal en la decisión civil, y que lleva a la Corte Suprema a sostener lo siguiente: "Al no existir responsable penal en la presente investigación, carece de todo fundamento la condena civil del acusado de autos, toda vez que solo en el evento de que alguien cometa un hecho ilícito y este se encuentra en relación de causalidad con el daño provocado, deberá ser indemnizado; por lo que no existiendo en el presente caso un autor culpable, consecuencialmente la demanda civil deberá ser rechazada" (cons. $12^{\circ}$ ).

Dos cuestiones, bastante relacionadas entre sí, solo podrán quedar planteadas en relación con los estándares de prueba: ¿Debe el juez esforzarse por ofrecer una explicación acerca de lo que realmente pasó o basta con que decida que no se acreditaron los hechos alegados? ${ }^{157}$ ¿Tienen los demandados que probar sus propias versiones acerca de cómo ocurrieron los hechos? Por ejemplo, si una Clínica sugiere que la muerte de una menor de dos años no se debió a un retraso en evaluar la lesión en su cráneo, sumado a un errado diagnóstico de resfrío por los vómitos que tuvo la niña (síntomas que provenían de una epilepsia sufrida a raíz de un TEC), sino que a un supuesto maltrato infantil (porque un médico de la Clínica así lo consignó en la ficha clínica de la niña, lo que dio lugar

156 Rebolledo con Sabat (en una operación de urgencia practicada a un paciente con varias heridas cortopunzantes en su intestino, se olvidó una pinza quirúrgica en su abdomen), C.S., 23 abril 2007 , Rol N ${ }^{\circ}$ 6585-06, MJCH_MJJ9619, cons. $4^{\circ}$ (Segunda Sala: redacción de Ministro Nibaldo Segura, quien votó en contra).

${ }^{157}$ Un ejemplo de esta “mejor explicación” puede leerse en Zúñiga y otros con Sociedad Clínica Francesa Limitada (una mujer de cuarenta y un año murió al nacer su hijo), C.A. Concepción, 17 marzo 2004, Rol 1295-2001, vLex: 32032952, cons. $8^{\circ}$ y $15^{\circ}$ (redacción del Ministro Guillermo Silva): "[Fue] un caso de alto riesgo obstétrico, por la edad de la paciente y la concomitancia de miomas uterinos; se produjo una eclampsia del puerperio inmediato, patología que según la literatura extranjera, tiene una mortalidad materna que supera al $50 \%$ de los casos [...] la ruptura hepática que se produce en la eclampsia, es uno de los cuadros más graves de la patología obstétrica, con una mortalidad materna muy alta (60 a $80 \%$ de los casos), incluso usándose los medios adecuados de que disponen los mejores centros médicos del mundo". 
a una investigación penal de la que la madre fue sobreseída ${ }^{158}$, ¿debe hacerse cargo de ello cuando se rinden las pruebas? ¿Qué ocurriría si no lo hiciese?

\section{Conclusiones}

La jurisprudencia chilena ha regulado la prueba de la responsabilidad civil médica sobre la base de dos pilares: la soberanía del juez de instancia para decidir cuándo han sido probados los hechos (estándar de prueba) y el reconocimiento del testimonio de los profesionales médicos como la mejor evidencia disponible en juicios de este tipo. Esta regulación se aplica tanto si se demanda por un tratamiento médico (profesionales) como por la organización del servicio de salud (Hospitales y Clínicas). Otras tendencias e inquietudes que giran en torno a este tema son las siguientes:

1. Los deberes de cuidado que deslindan entre la injusticia y el infortunio varían según se trate de un profesional (tratamiento) o de los Hospitales y Clínicas (organización), pero en ambos casos las condiciones de la responsabilidad apelan a ideas como guiarse por razones, controlar la conducta y actuar dentro de un ámbito de competencia segura (o fuera de él, a sabiendas);

2. Mientras que la culpa (o la falta de servicio) actúa como un factor de imputación (regla de entrada), su contracara - la diligencia- opera como un límite a la responsabilidad civil, aunque en la práctica a la regla de salida que se acude con más frecuencia es a la causalidad;

3. El conocimiento de las reglas de entrada y de salida de la responsabilidad médica, por parte de abogados y jueces, permite saber con anticipación qué hechos se someterán a prueba en estos juicios (objeto procesal, auto de prueba, puntos de prueba), aunque siempre hay un margen de maniobra según el caso;

4. Existe un sentido en que, tratándose de las cuestiones de hecho, el juez considera a los litigantes como representantes de una clase de personas (servicios de urgencia, pacientes en reposo, cirujanos plásticos) y no como individuos, lo que le permite a la jurisprudencia participar tanto en la creación de las reglas de prueba, como en su evolución y cambio;

5. La necesidad del testimonio de los expertos en salud ha llevado a presumir judicialmente su imparcialidad cuando declaran en juicio, aunque las tachas sirvieron para levantar la alarma de una eventual protección corporativa de intereses por parte de los médicos, Clínicas y Hospitales;

6. Casi no existe reflexión en torno a los márgenes de inmunidad del experto cuando declara en juicio, así como tampoco concerniente a la exclusión de pruebas en razón de su ilicitud, ni de los límites a la confidencialidad de la información médica del paciente;

${ }^{158}$ De Vidts con Pontificia Universidad Católica de Chile, C.S., 29 septiembre 1998, MJCH_MJJ1123 (redacción del Abogado Integrante Fernando Castro); también en Revista de Derecho y Jurisprudencia, Tomo XCV, sec. $1^{\mathrm{a}}$. 
7. El juez civil es soberano para darle o restarle peso al testimonio de los expertos, aunque no domine la disciplina de estos;

8. Las máximas de la experiencia ayudan al juez a comprender la información de que dispone, tanto a efectos de establecer la culpa, la causalidad y el daño (sobre todo moral), como al cuantificar en dinero esos perjuicios;

9. Los jueces, la academia y la propia legislación parecen manejar distintas ideas acerca de los fines y funciones de la carga de la prueba. Si su función es dirimir quién aportará los datos al proceso, con el fin de hacer más probable que el juez conozca el conflicto en sus términos relevantes, tiene sentido proponer una carga de la prueba compartida por ambos litigantes tratándose de obligaciones de medio;

10. La competencia exclusiva del juez de instancia para decidir los hechos probados (soberanía judicial) ha posicionado a su convicción como el estándar de prueba civil, aunque ella -entendida como algo subjetivo- es un falso estándar, pues deforma el sentido de motivar las sentencias y no es coherente con el sistema de recursos procesales vigente. En su lugar debería regir el estándar de la probabilidad prevaleciente $(\mathrm{P}>0,5)$, con una aplicación común y supletoria;

11. Cuando la Corte Suprema se refiere a la competencia del juez de instancia para juzgar los hechos nunca aclara si se refiere al juez de primera instancia o a los de segunda instancia;

12. El juez debe fallar sobre la base de un juicio de hecho posible, probable y que tenga mayor peso probatorio que los demás juicios que compiten por explicar el caso;

13. En ocasiones los jueces civiles se esfuerzan por explicar el origen más probable del daño, pero no existe claridad en cuanto a si tienen el deber de hacerlo;

14. Cada vez que un juez descarta la responsabilidad civil únicamente porque desestimó la responsabilidad penal, pasa por alto los compromisos que están detrás de los estándares de prueba y protege más de la cuenta al demandado de responder civilmente por los daños;

15. En varias ocasiones el res ipsa loquitur es utilizado en su versión débil, como una autorización para que el juez acoja la demanda y coloque los riesgos de error sobre los hombros de la demandada.

16. Por último, varios de estos temas exceden el ámbito propio de la responsabilidad civil médica y forman parte del enigma de las leyes reguladoras de la prueba. Es esta leyenda judicial la que precisa de un análisis exhaustivo para saber si la justicia chilena se toma realmente en serio la prueba de los hechos. Pero ese es un tema para otro trabajo.

\section{BIBLIOGRAFÍA}

Barros, E., Tratado de responsabilidad extracontractual, Editorial Jurídica de Chile, Santiago, 2006, $1230 \mathrm{pp}$.

Beswick, J., "Commentary. A First Class Service? Setting the Standard of Care for the Contemporary NHS. Garcia v. St. Mary's NHS Trust [2006] E.W.H.C. 2314 (QBD)”, en Medical Law Review, 15, 2007, pp. 245-252. 
Cane, P., Anatomía del derecho de daños, traducción de Arturo Carvallo y Pablo Becerra, Editorial Flandes indiano, Santiago de Chile, 2011 (1997), 339 pp.

CÁrdenas, H. y Moreno, J., Responsabilidad médica. Estándares jurisprudenciales de la falta de servicio, Thomson Reuters, Santiago de Chile, 2011, 285 pp.

Chabas, F., "Aspectos generales de la responsabilidad médica en Francia”, en Publicaciones Doctorado en Derecho Universidad de Chile, Santiago de Chile, 2005, pp. 23-27.

Cortés, E., "Culpa y responsabilidad médica en Colombia y Chile”, en Roma e America. Rivista di Diritto dell'Integrazione e Unificazione del Diritto en Europa e in America Latina, Mucchi Editore, 21, 2006, pp. 181-198.

Devaney, S., "Commentary. Balancing Duties to the Court and Client: The Removal of Immunity from Suit of Expert Witness. Jones v. Kaney [2011] UKSC 13”, en Medical Law Review, 20, 2012, pp. 450-459; "Commentary. The Loneliness of the Expert Witness. General Medical Council v. Meadow [2006] E. W.C.A 1390”, en Medical Law Review, 15, 2007, pp. 116-125.

Domínguez, C., "El problema de la culpa presunta contractual y las obligaciones de medio y resultado: sus implicancias para la responsabilidad médica”, en Cuadernos de Análisis Jurídico, Íñigo de la Maza compilador, Universidad Diego Portales, VI, 2010, pp. 21-44.

Domínguez, R., "Comentarios de jurisprudencia. Necesidad de prueba del daño moral. No basta acreditar un vínculo de filiación”, en Revista de Derecho, Universidad de Concepción, $\mathrm{N}^{\circ}$ 225-226, 2009, pp. 295-298.

Ho, H. L., A Philosophy of Evidence Law. Justice in the Search for Truth, Oxford Monographs on Criminal Law, Oxford University Press, 2008, 347 pp.

Jana, A. y Tapia, M., "Daño moral en la responsabilidad contractual. A propósito de un fallo de la Corte Suprema de 5 de noviembre de 2001", en Cuadernos de Análisis Jurídicos, Universidad Diego Portales, I, 2004, pp. 171-209.

Larroucau, J., "Hacia un estándar de prueba civil", en Revista Chilena de Derecho, Pontificia Universidad Católica de Chile, Vol. 39, No 3, 2012, pp. 783-808;

- "Por un estándar amplio de admisibilidad de pruebas en la justicia civil", en Actas del Congreso Internacional de Derecho. En homenaje al Centenario de la Escuela de Derecho de la Universidad de Valparaíso, Tomo IV, EDEVAL, Valparaíso, 2012, pp. 185-218;

- "Res ipsa loquitur: Quien habla es el juez, no la cosa", en Estudios de Derecho Civil VI, Gonzalo Figueroa, Enrique Barros y Mauricio Tapia (coord.), LegalPublishing, Santiago de Chile, 2011, pp. 491-519;

- Culpa y dolo en la responsabilidad extracontractual. Análisis jurisprudencial, LegalPublishing, Santiago de Chile, 2007, 4a reimpresión, 2010, 233 pp.

Lord, Irvine, "The Patient, the Doctor, their Lawyers and the Judge: Rights and Duties", en Medical Law Review, 7, 1999, pp. 255-268.

Lord, Woolf, "Are the Courts Excessively Deferential to the Medical Profession?", en Medical Law Review, 9, 2001, pp. 1-16.

LunA, Á., "Oblit d'una gasa durant una intervenció quirúrgica”, en InDret, Barcelona, 2, 2003, pp. 1-14.

PeÑallillo, D., La prueba en materia sustantiva civil. Parte general, Editorial Jurídica de Chile, Santiago, 1989, $126 \mathrm{pp}$.

Pizarro, C., "Obligaciones y responsabilidad civil", en Revista Chilena de Derecho Privado, Universidad Diego Portales, $N^{\circ} 17,2011$, pp. 241-245; "La culpa como elemento constitutivo del incumplimiento en las obligaciones de medio o de diligencia", en Revista de Derecho, Pontificia Universidad Católica de Valparaíso, XXXI, 2008, pp. 255-265; "La responsabilidad civil médica por el hecho ajeno", en Revista Chilena de Derecho Privado, Universidad Diego Portales, $\mathrm{N}^{\circ} 1,2003$, pp. 181-205. 
Porat, A. y Stein, A., Tort Liability under Uncertainty, Oxford University Press, 2001, 214 pp. Puppe, I., "División del trabajo y de la responsabilidad en la actuación médica", traducción de Nuria Pastor, en InDret, Barcelona, 4, 2006, pp. 1-13.

RAz, J., "Responsibility and the Negligence Standard", en Oxford Journal of Legal Studies, Vol. 30, No 1, 2010, pp. 1-18.

Robertson, A., "On the Function of the Law of Negligence", en Oxford Journal of Legal Studies, Vol. 33, $\mathrm{N}^{\circ} 1,2013$, pp. 31-57.

Stein, A., "Toward a Theory of Medical Malpractice”, en Iowa Law Review, 97, 2012, pp. 12011257; "Contra la 'prueba libre'”, traducción de Jorge Larroucau Torres, en Revista de Derecho, Universidad Austral, Vol. 26, No 2, 2013 (1997), pp. 245-261; "The Refoundation of Evidence Law", en Canadian Journal of Law E Jurisprudence, Vol. 9, 1996, pp. 279-342.

Twining, W., "Debating Probabilities”, en The Liverpool Law Review, 2, 1980, pp. 51-64.

Zelaya, P., "Responsabilidad civil de hospitales y clínicas (modernas tendencias jurisprudenciales)", en Revista de Derecho, Universidad de Concepción, No 201, 1997, pp. 11-58. 
